\title{
Reparative Effects of Stem Cell Factor and Granulocyte Colony-Stimulating Factor in Aged APP/PS1 Mice
}

\author{
Xingzhi Guo ${ }^{1}$, Yanying Liu ${ }^{1}$, David Morgan ${ }^{2}$, Li-Ru Zhao ${ }^{1 *}$ \\ ${ }^{1}$ Department of Neurosurgery, State University of New York Upstate Medical University, Syracuse, New York, \\ 13210, USA \\ ${ }^{2}$ Translational Neuroscience, Michigan State University, College of Human Medicine, Grand Rapids, Michigan, \\ 49503, USA
}

[Received November 18, 2019; Revised January 28, 2020; Accepted February 1, 2020]

\begin{abstract}
Alzheimer's disease (AD), characterized by the accumulation of $\beta$-amyloid (A $\beta$ ) plaques and tau neurofibrillary tangles in the brain, neuroinflammation and neurodegeneration, is the most common form of neurodegenerative disease among the elderly. No effective treatment is available now in restricting the pathological progression of $\mathrm{AD}$. The aim of this study is to determine the therapeutic efficacy of stem cell factor (SCF) and granulocyte colony-stimulating factor (G-CSF) (SCF+G-CSF) in aged APPswe/PS1dE9 (APP/PS1) mice. SCF+G-CSF was subcutaneously injected for 12 days to 25-month-old male APP/PS1 mice. We observed that SCF+G-CSF treatment reduced the A $\beta$ plaques in both the cortex and hippocampus. SCF+G-CSF treatment increased the association of $\mathrm{TREM2}^{+} / \mathrm{Iba} 1^{+}$cells with $\mathrm{A} \beta$ plaques and enhanced $\mathrm{A} \beta$ uptake by $\mathrm{Iba}^{+}$and $\mathrm{CD68}^{+}$cells in the brains of aged APP/PS1 mice. Importantly, cerebral expression area of P2RY12 and $\mathrm{TMEM}_{119}{ }^{+}$homeostatic microglia and the branches of P2RY12 ${ }^{+}$homeostatic microglia were increased in the SCF+G-CSF-treated aged APP/PS1 mice. SCF+G-CSF treatment also decreased NOS-2 and increased IL-4 in the brains of aged APP/PS1 mice. Moreover, the loss of MAP2 ${ }^{+}$dendrites and PSD-95 ${ }^{+}$post-synapses and the accumulation of aggregated tau in the brains of aged APP/PS1 mice were ameliorated by SCF+G-CSF treatment. Furthermore, the density of $\mathrm{P} 2 \mathrm{RY} 12^{+}$microglia was negatively correlated with $\mathrm{A} \beta$ deposits, but positively correlated with the densities of MAP2 ${ }^{+}$dendrites and PSD-95 ${ }^{+}$puncta in the brains of aged APP/PS1 mice. These findings reveal the therapeutic potential of SCF+G-CSF treatment in ameliorating AD pathology at the late stage.
\end{abstract}

Key words: Alzheimer's disease, $\beta$-amyloid, granulocyte colony-stimulating factor, stem cell factor, microglia, neuroinflammation

Alzheimer's disease (AD) is the most common neurodegenerative disease in the elderly, which leads to huge economic costs and social burden worldwide [1]. In the United States, an estimated 5.8 million Americans were living with $\mathrm{AD}$ in 2019 , and $97 \%$ of $\mathrm{AD}$ individuals are age 65 and older [2].

The pathological hallmarks of $\mathrm{AD}$ are characterized by the presence of amyloid beta $(\mathrm{A} \beta)$ plaques, intracellular neurofibrillary tangles, and neuro- inflammation $[3,4]$. The $\mathrm{A} \beta$, a peptide with $40-42$ amino acids, is derived from the amyloid precursor protein (APP) through sequentially proteolytic cleavages by the $\beta$-secretase and $\gamma$-secretase [5]. Overproduction or insufficient clearance of $A \beta$ leads to $A \beta$ aggregation, and the pathological accumulation of oligomeric $A \beta$ is crucially involved in neuronal dysfunction, neuronal network destabilization and cognitive impairment [6]. Moreover, intracerebral injection of aggregated $\mathrm{A} \beta$ (25-35)

*Correspondence should be addressed to: Dr. Li-Ru Zhao, Department of Neurosurgery, State University of New York Upstate Medical University, Syracuse, New York 13210. USA. E-mail: ZHAOL@upstate.edu.

Copyright: $\odot 2020$ Guo X et al. This is an open-access article distributed under the terms of the Creative Commons Attribution License, which permits unrestricted use, distribution, and reproduction in any medium, provided the original author and source are credited. 
chronically activates microglia, resulting in persistent neuroinflammation [7]. It has been reported that inhibiting $\mathrm{A} \beta$ plaque formation protects against dendritic spine loss and prevents cognitive deficits in an APP mouse model of $\mathrm{AD}$ [8]. Therefore, to prevent $\mathrm{A} \beta$ accumulation or promote $\mathrm{A} \beta$ removal has been deemed the main therapeutic target for AD [9-11]. Over the past decades, tremendous efforts have been made to develop treatment for $\mathrm{AD}$, while effective medications have not yet been available to stop, delay or reverse the pathological progression of AD [11]. Anti-A $\beta$ immunotherapy with anti-A $\beta$ antibodies has been thought to be a hopeful therapeutic strategy for $\mathrm{AD}$ [12-16]. A long-term study of monthly administration of a human monoclonal antibody, aducanumab, to mild $\mathrm{AD}$ patients for one year has shown reduced brain $A \beta$ and slowed cognitive decline [12], leading to more recent AD clinical trials. However, lack of efficacy or the adverse effects (e.g. amyloid-related imaging abnormalities) found in clinical trials, and considerable costs of long-term treatment limit the usage of this therapy in AD [12,16-19]. Therefore, to develop new effective and safe pharmaceutical approaches is an urgent need for preventing or delaying the progression of AD.

Stem cell factor (SCF) and granulocyte colonystimulating factor (G-CSF) were originally demonstrated as essential hematopoietic growth factors regulating the proliferation, differentiation and mobilization of hematopoietic stem cells (HSCs) [20, 21]. SCF in combination with G-CSF ( $\mathrm{SCF}+\mathrm{G}-\mathrm{CSF}$ ) synergistically enhances the proliferation, differentiation, and survival of $\mathrm{HSCs} /$ hematopoietic progenitor cells (HPCs) [22], and synergistically mobilizes HSCs/HPCs into the blood stream [23-25]. The biologic synergy between SCF and G-CSF has also been demonstrated in the central nervous system. SCF+G-CSF synergistically promotes neurite outgrowth and neural network structural formation of cultured cortical neurons through PI3K/AKT/NF$\mathrm{kB} / \mathrm{BDNF}$ pathway [26]. SCF+G-CSF treatment in the chronic phase of experimental stroke leads to stable and long-term improvements in somatosensory motor function as compared to SCF and G-CSF alone treatments [27], and enhances neural network regrowth and synaptogenesis $[28,29]$.

In clinical studies, decreased levels of SCF and GCSF in the plasma have been observed in $\mathrm{AD}$ patients [30, 31]. It remains to be determined, however, whether exogenous administration of SCF and G-CSF could ameliorate pathological severity in $\mathrm{AD}$. In our earlier study, we have revealed that systemic administration of SCF+G-CSF in middle aged (9 months) APP/PS1 mice results in long-term ( 9 months) reductions in $\mathrm{A} \beta$ deposits [32]. Since AD predominantly affects elderly people, it is highly important to determine the efficacy of SCF+G-
CSF treatment in $\mathrm{A} \beta$ removal, neuroinflammatory modulation, and rebuilding neuronal connections in aged APP/PS1 mice.

In the present study, 25-month-old APP/PS1 mice received 12-days of SCF+G-CSF injections. As an initial study exploring pharmaceutical strategy for $\mathrm{AD}$ at such an old age, we have demonstrated that $\mathrm{SCF}+\mathrm{G}-\mathrm{CSF}$ treatment reduces $\mathrm{A} \beta$ deposits, ameliorates neuroinflammation, and increases the densities of dendrites and synapses in the brains of the very old APP/PS1 mice.

\section{MATERIALS AND METHODS}

\section{Animals}

The experiments have been carried out in accordance with the National Institutes of Health Guidelines for the Care and Use of Laboratory Animals in the United States. All experimental procedures have been approved by the Animal Care and Use Committees of State University of New York Upstate Medical University (IACUC\#369).

APPswe/PS1dE9 (APP/PS1) transgenic mice coexpressing Swedish double mutations (K595N/M596L) of amyloid precursor protein (APP) together with mutant human presenilin protein 1 (PS1) carrying the exon-9deleted variant (PS1-dE9)[33] were used in this study (stock\# 34832, The Jackson Laboratory, Bar Harbor, Maine, USA). The APP/PS1 mice with C57BL/6J genetic background develop $A \beta$ deposits in the brain at 6-7 months of age [34]. Mice were housed in a standard laboratory environment $(12 \mathrm{~h} \mathrm{light} / 12 \mathrm{~h}$ dark regime at 22 ${ }^{\circ} \mathrm{C}$ ) and were given free access to food and water.

\section{Experimental Design}

A total of 20 male APP/PS1 mice were prepared for this study ( $n=10$ /group). At the age of $\sim 25$ months, nine of them remained. These aged APP/PS1 mice and five agematched C57BL/6J wild type (WT) mice (The Jackson Laboratory, Bar Harbor, Maine, USA) were used in this study. The APP/PS1 mice were randomly divided into two groups and subcutaneously injected with recombinant mouse SCF (200 $\mu \mathrm{g} / \mathrm{kg} / \mathrm{day}$; PeproTech, Rocky Hill, NJ, USA) and recombinant human G-CSF $(50 \mu \mathrm{g} / \mathrm{kg} /$ day; Amgen, Thousand Oaks, CA, USA) $(\mathrm{SCF}+\mathrm{G}-\mathrm{CSF})(\mathrm{n}=4)$ or vehicle solution (saline and $5 \%$ dextrose) $(\mathrm{n}=5)$ once a day for 12 days. Recombinant SCF and G-CSF have been shown to pass through the blood-brain barrier in intact animals [35]. The doses [36, 37] and treatment duration [32] for SCF+G-CSF intervention were selected in the present study based on the effective paradigm demonstrated in our earlier studies. Six weeks after injection of SCF+G-CSF or vehicle, all the APP/PS1 and 
WT mice were sacrificed, and the brains were collected for immunohistochemistry/histochemistry (Fig. 1). We chose to examine the effects of treatment at six weeks post-treatment because our previous study in aged mice with chronic stroke has shown increased dendrites and synapses in the cortex six weeks after SCF+G-CSF treatment [28].

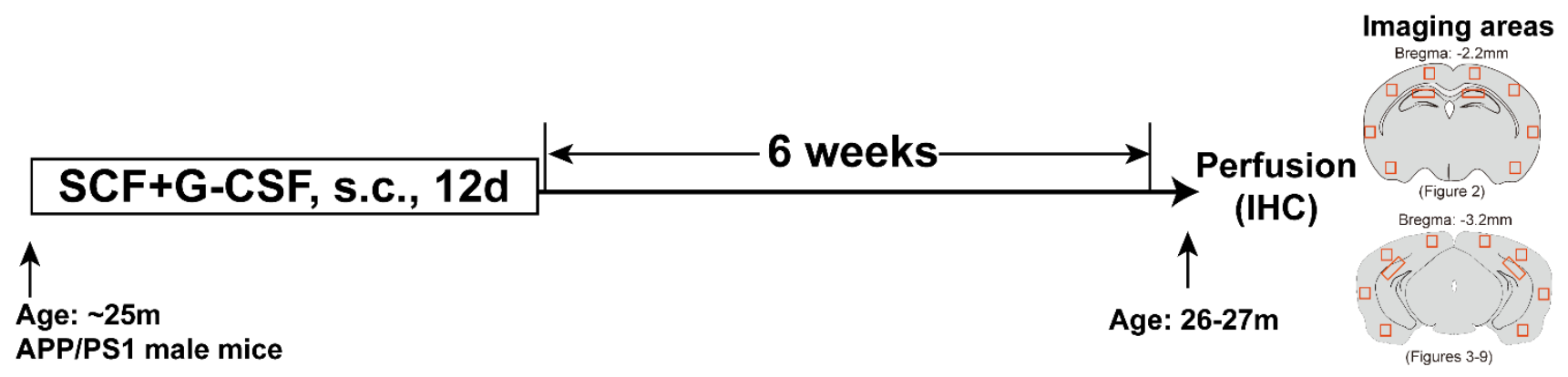

Figure 1. Experimental flowchart and imaging areas in the brain sections. Mouse brain diagrams illustrate the brain regions and the areas for imaging in the cortex and hippocampus. s.c., subcutaneously; IHC, immunohistochemistry.

\section{Immunohistochemistry and histochemistry}

Mice were transcardially perfused with phosphate buffered saline (PBS) followed by $4 \%$ buffered formaldehyde (Sigma-Aldrich, St. Louis, MO, USA). The brains were removed, placed in $4 \%$ buffered formaldehyde overnight at $4^{\circ} \mathrm{C}$, and then cryoprotected by immersion in $30 \%$ sucrose. Coronal brain sections $(30 \mu \mathrm{m}$ thick) were cut with a microtome (Leica SM 2000R, Nussloch, Germany). Two or three brain sections from each brain were processed for immunohistochemistry or histochemistry. The free-floating method was used for immunohistochemistry. Briefly, to minimize endogenous mouse $\operatorname{IgG}$ background staining when using mouse primary antibodies, sections were incubated with mouse on mouse (MOM) solution (Vector Laboratories, Burlingame, CA, USA) for $1 \mathrm{~h}$ at room temperature. After being washed with PBS $(3 \times 5 \mathrm{~min})$, nonspecific binding was blocked by $10 \%$ normal donkey serum in $1 \%$ bovine serum albumin (IgG-free, protease free, Jackson ImmunoResearch Labs, West Grove, PA, USA) and 0.25\% Triton X-100 (Sigma-Aldrich, St. Louis, MO, USA) for $1 \mathrm{~h}$ at room temperature. Brain sections were then incubated with primary antibodies overnight at $4{ }^{\circ} \mathrm{C}$. The primary antibodies include mouse anti- $\beta$-amyloid (1:1000) (clone 4G8, Biolegend, Dedham, MA, USA, \#800701), mouse anti- $\beta$-amyloid (1:1000) (clone 6E10, Biolegend, Dedham, MA, USA, \#803004), rabbit antiIba1 (Ionized calcium binding adaptor molecule 1) (1:400, Wako, Osaka, Japan, \#019-19741), goat anti-Iba1 (1:400, Novus Biologicals, CO, USA, \#NB100-1028), rabbit anti-P2RY12 (purinergic receptor P2Y, G-protein coupled, 12) (1:500, Brigham and Women's Hospital, MA, USA), rabbit anti-MAP2 (microtubule associated protein 2) (1:600, Millipore Corporation, MA, USA,
\#AB5622), mouse anti-PSD-95 (postsynaptic density protein 95) (1:500, Novus Biologicals, CO, USA, \#NBP212872), sheep anti-TREM2 (triggering receptor expressed on myeloid cells-2) (1:300, R\&D Systems, Minneapolis, USA, \#AF1729), NOS2 (1:100, Millipore Corporation, MA, USA, \#AB5382), IL-4 (1:50, Thermo Fisher Scientific, Waltham, MA, USA, \# PA5-25165), NeuN (1:500, Millipore Corporation, MA, USA, \#MAB377), GFAP (1:500, Sigma-Aldrich, St. Louis, MO, USA, \#G3893), CD68 (1:300, Bio-Rad, Hercules, CA, USA, \#MCA1957GA), TMEM119 (1:1000, Abcam, Cambridge, MA, \#ab209064), and AT8 (1:400, Thermo Fisher Scientific, Waltham, MA, USA, \#MN1020). After being washed with PBS $(3 \times 10 \mathrm{~min})$, the sections were incubated with Alexa Fluor 488-, 594- or 647-conjugated donkey anti-mouse, rabbit, goat or sheep secondary antibodies (Thermo Fisher Scientific, Waltham, MA, USA) for $2 \mathrm{~h}$ at room temperature in the dark. After being washed with PBS $(3 \times 10 \mathrm{~min})$, sections were mounted with Vectashield antifade mounting medium containing 4', 6-diamidino-2-phenylindole (DAPI) (Vector Laboratories, Burlingame, CA, USA, \#H-1500).

For X-34 (Sigma-Aldrich, St. Louis, MO, USA) and Collagen-IV staining, Tris-EDTA Buffer (10mM Tris Base, 1mM EDTA Solution, pH 9.0) was used for antigen retrieval before staining. Briefly, after being washed with PBS for $5 \mathrm{~min}$, the sections were put into pre-heated antigen retrieval buffer $(500 \mathrm{ml})$ at $90^{\circ} \mathrm{C}$ for $10 \mathrm{~min}$ and then cooled to room temperature. After PBS washing $(3 \times$ $5 \mathrm{~min}$ ), the sections were rinsed with $\mathrm{ddH}_{2} \mathrm{O}$ for $2 \mathrm{~min}$. The sections were then put into $100 \mu \mathrm{M} \mathrm{X}-34$ working solution $(\mathrm{pH}=10)$ for $10 \mathrm{~min}$ at room temperature in the dark. After being washed with $\mathrm{ddH}_{2} \mathrm{O}(5 \times 2 \mathrm{~min})$, the sections were differentiated for 2 min with $0.2 \% \mathrm{NaOH}$. After PBS washing $(2 \times 5 \mathrm{~min})$, the sections were then incubated 
with Col-IV antibody (rabbit anti-Col-IV, 1:300, Abcam, Cambridge, MA, \#ab6586) overnight at $4^{\circ} \mathrm{C}$ and incubated with Alexa Fluor 594-conjugated donkey antirabbit for $2 \mathrm{~h}$ at room temperature following the standard immunohistochemistry protocol described above. Finally, the sections were mounted with Vectashield antifade mounting medium without DAPI (Vector Laboratories, Burlingame, CA, USA, \#H-1700). Brain sections with the omission of primary antibodies served as negative controls (Supplementary Fig. 1).

\section{Quantification of immunohistochemistry and histo- chemistry}

To determine the $A \beta$ deposition in the brain, images were obtained using a Zeiss-inverted microscope (AxioVision 4.8, Carl Zeiss AG, Gottingen, Germany) and quantified using ImageJ software. Images were taken from eight selected areas in the cortex (bregma, $-1.2 \mathrm{~mm}$ ) and 6 selected areas in the hippocampus (bregma, $-2.2 \mathrm{~mm}$ ) of each brain section using a $20 \times$ or $40 \times$ objective lens (Fig. 1). Plaque number, plaque area and average $A \beta$ size were calculated in $20 \times$ images using the "analyze particles plugin" of ImageJ. The A $\beta$ area fraction was determined by dividing the total plaque area by the area of the microscopic field.

For the rest of immunohistochemistry quantification, four random areas in the cortex and $1 \times 3$ tile scan areas in the CA1 region (bregma, $-3.2 \mathrm{~mm}$ ) of each hemisphere were selected to capture images from each brain section using a confocal microscope (Zeiss LSM780) with a $20 \times$ or $40 \times$ objective lens (Fig. 1). In the analysis of $A \beta$ phagocytosis by Iba1 positive cells, images (12 z-stacks with $1 \mu \mathrm{m}$ intervals, $1024 \times 1024$ pixels) were taken using the Zeiss LSM780 confocal microscope. The colocalization of Iba1 positive cells and 4G8 positive A $\beta$ was quantified by using the $3 \mathrm{D}$ plugin in ImageJ. The volume of $4 \mathrm{G}^{+}$senile plaques within $\mathrm{Iba}^{+}$cells surrounding the senile plaques in each image field was calculated. The $A \beta$ uptake volume was determined by dividing the $\mathrm{Iba} 1^{+} / 4 \mathrm{G}^{+}$colocalization volume by the total $\mathrm{Iba}^{+}$cell volume. For quantification of Iba1, TREM2, CD68, P2RY12, TMEM119, AT8, NOS-2 and IL-4 immunopositive staining, images (12 z-stacks with $1 \mu \mathrm{m}$ intervals, $1024 \times 1024$ pixels) were taken with the Zeiss LSM780 confocal microscope using the $40 \times$ lens. After the images were stacked with the maximum approach, the immunopositive staining of Iba1, TREM2, CD68, P2RY12, TMEM119, AT8, NOS-2 and IL-4 was quantified by dividing the total immunopositive staining area by the area of the image field using ImageJ.

For quantification of MAP2 staining, images were captured with the Zeiss LSM780 confocal microscope using the tile scan feature with an average grid size of $3 \times$
5 taken with the $40 \times$ objective at a resolution of $1024 \times$ 1024 pixels. The MAP2 $2^{+}$immunostaining in the cortex and CA1 was determined by dividing the MAP2 positive area by the area of the image field of the entire cortex or selected CA1 region using Image J. For quantification of PSD-95 staining, images $(1024 \times 1024$ pixels $)$ were taken by using the Zeiss LSM780 confocal microscope with the $40 \times$ lens. The number of PSD-95-labeled puncta in the cortex and CA1 was counted automatically with a threshold of 20 pixels in ImageJ.

For quantification of $\mathrm{X}-34^{+} \mathrm{A} \beta$ deposition and Col$\mathrm{IV}^{+}$blood vessels, images were taken with the Zeiss LSM780 confocal microscope using the $20 \times$ lens. The $\mathrm{X}$ 34 and Col-IV positive staining were quantified by dividing X-34 and Col-IV positive area by the area of the image fields in the cortex or CA1 using ImageJ.

For all image analysis, the background fluorescence of secondary antibodies was established as a threshold to be subtracted from the positive staining during data analysis using ImageJ.

\section{Statistical analysis}

Using Prism 6.0 software, comparisons among three groups were analyzed by one-way ANOVA followed by Fisher's LSD test, and the comparisons between two groups were analyzed by unpaired student's t-test. Pearson correlation analysis was used to evaluate the correlative association between $\mathrm{X}-34^{+} \mathrm{A} \beta$ deposition and $\mathrm{P}^{2} \mathrm{RY}_{12} 2^{+}$cells, between $\mathrm{P} 2 \mathrm{RY} 12^{+}$cells and $\mathrm{MAP}^{+}$ dendrites, and between P2RY12 ${ }^{+}$cells and PSD-95 ${ }^{+}$ synapses. All data are expressed as mean \pm S.E.M. Statistical significance was considered $\mathrm{p}<0.05$.

\section{RESULTS}

\section{SCF plus G-CSF treatment reduces $\beta$-amyloid deposition in aged APP/PS1 mice}

To determine the effects of SCF+G-CSF treatment on $\mathrm{A} \beta$ removal in aged male APP/PS1 mice, immunehistochemistry was performed to determine $4 \mathrm{G} 8$ positive compact fibrillar $A \beta$ and diffuse $A \beta[38]$ in the cortex and hippocampus. We observed that there were numerous $4 \mathrm{G}^{+} \mathrm{A} \beta$ deposits in the cortex and hippocampus of APP/PS1 mice, while SCF+G-CSF treatment significantly reduced the percentage area of $4 \mathrm{G}^{+} \mathrm{A} \beta$ deposits in both the cortex $(\mathrm{p}<0.01)$ and hippocampus $(\mathrm{p}<0.05)$ (Fig. 2A, B, E). In addition, the number of $4 \mathrm{G}^{+}$ $\mathrm{A} \beta$ plaques in the cortex was significantly decreased in the SCF+G-CSF-treated APP/PS1 mice as compared to the vehicle controls ( $\mathrm{p}<0.001)$ (Fig. 2C). A similar result was also found in the hippocampus (vehicle control vs. $\mathrm{SCF}+\mathrm{G}-\mathrm{CSF}, \mathrm{p}<0.05$ ) (Fig. 2F). Moreover, the $\mathrm{SCF}+\mathrm{G}-$ 
CSF treatment also significantly reduced the average size of $4 \mathrm{G} 8^{+} \mathrm{A} \beta$ plaques in the cortex and hippocampus $(\mathrm{p}<0.05)$ (Fig. 2D, G). These findings suggest that
$\mathrm{SCF}+\mathrm{G}-\mathrm{CSF}$ treatment in aged APP/PS1 mice reduces the load of diffuse $A \beta$ and compact fibrillar $A \beta$ in the cortex and hippocampus.
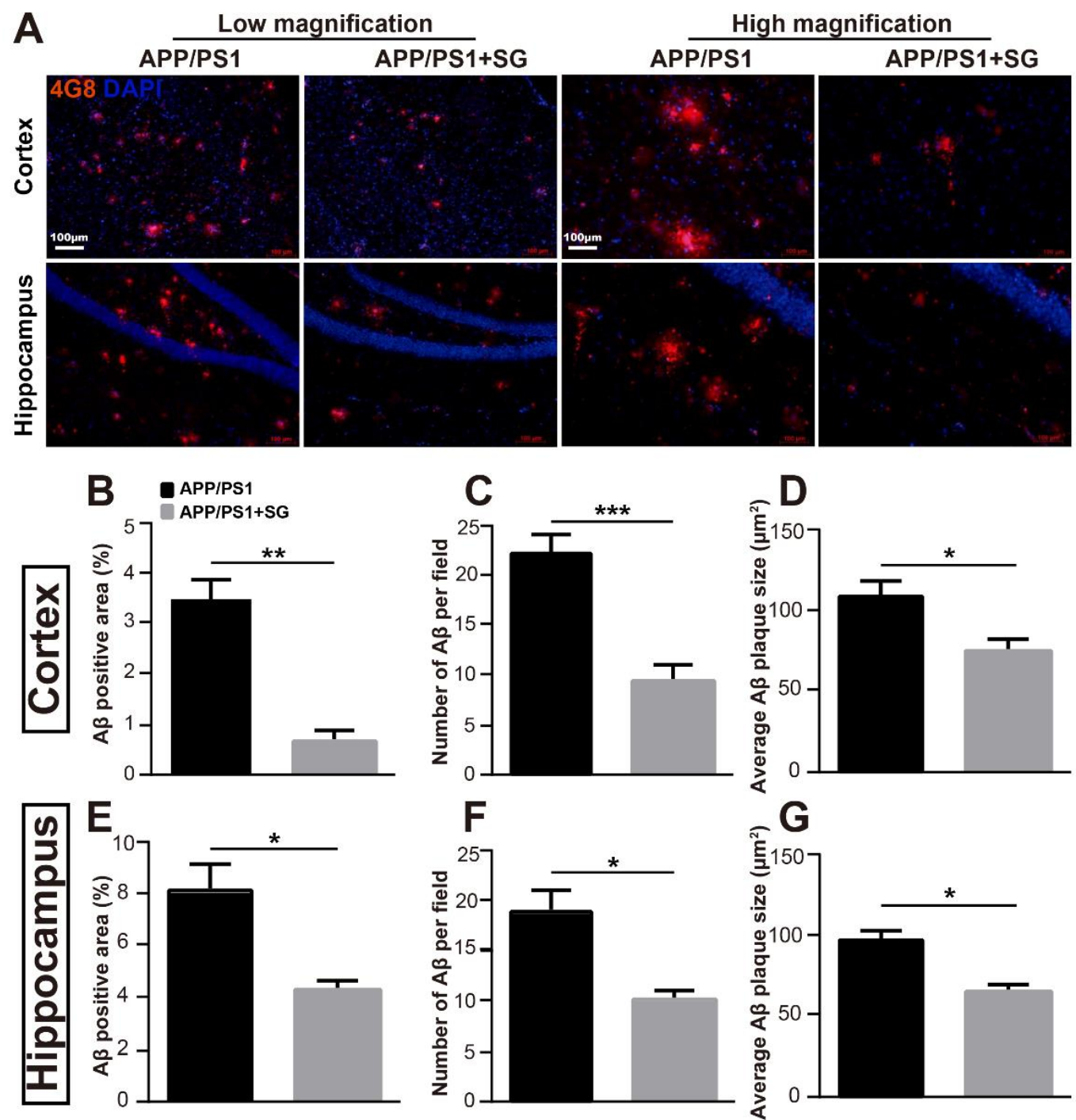

Figure 2. SCF+G-CSF treatment reduces A $\beta$ deposits in the brains of aged APP/PS1 mice. (A) Representative images of $4 \mathrm{G}^{+}$(red) $\mathrm{A} \beta$ deposits in the cortex and hippocampus with both low magnification and high magnification. (B-D) Quantification data show the percentage of $4 \mathrm{G} 8^{+} \mathrm{A} \beta$ area (B), the number of $4 \mathrm{G} 8^{+} \mathrm{A} \beta$ plaques (C) and the average size of $4 \mathrm{G} 8^{+} \mathrm{A} \beta$ plaques (D) in the cortex of aged APP/PS1 male mice treated with or without SCF+G-CSF. (E-G) Quantification data illustrate the percentage of $4 \mathrm{G} 8^{+} \mathrm{A} \beta$ area $(\mathbf{E})$, the number of $4 \mathrm{G}^{+} \mathrm{A} \beta$ plaques $(\mathbf{F})$ and the average size of $4 \mathrm{G} 8^{+} \mathrm{A} \beta$ plaques $(\mathbf{G})$ in the hippocampus of aged APP/PS1 mice treated with or without SCF+G-CSF. Blue: Nuclear counterstaining by 4',6-diamidino-2phenylindole (DAPI). SG: SCF+G-CSF. N=4-5. Mean \pm SEM. $* p<0.05, * *_{p}<0.01, * * * p<0.001$ by Student's t-test.

Fibrillar $A \beta$ is the primary constituent of amyloid plaques in the brain of $\mathrm{AD}[39,40]$. X-34 staining detects the compact fibrillar $A \beta$ [41]. To further confirm the contribution of $\mathrm{SCF}+\mathrm{G}-\mathrm{CSF}$ treatment in $\mathrm{A} \beta$ clearance, we utilized X-34 staining to assess the compact fibrillar $\mathrm{A} \beta$ plaques in the brains of APP/PS1 mice. We observed that the SCF+G-CSF-treated APP/PS1 mice showed significant reductions in the number (Fig. 3A and B) and percentage areas (Fig. 3C) of $\mathrm{X}-34$ positive plaques in both the cortex and hippocampal CA1 region $(\mathrm{p}<0.05)$. This observation indicates that systemic administration of $\mathrm{SCF}+\mathrm{G}-\mathrm{CSF}$ in aged APP/PS1 mice leads to reduction of compact fibrillar $A \beta$ in the cortex and hippocampus. 

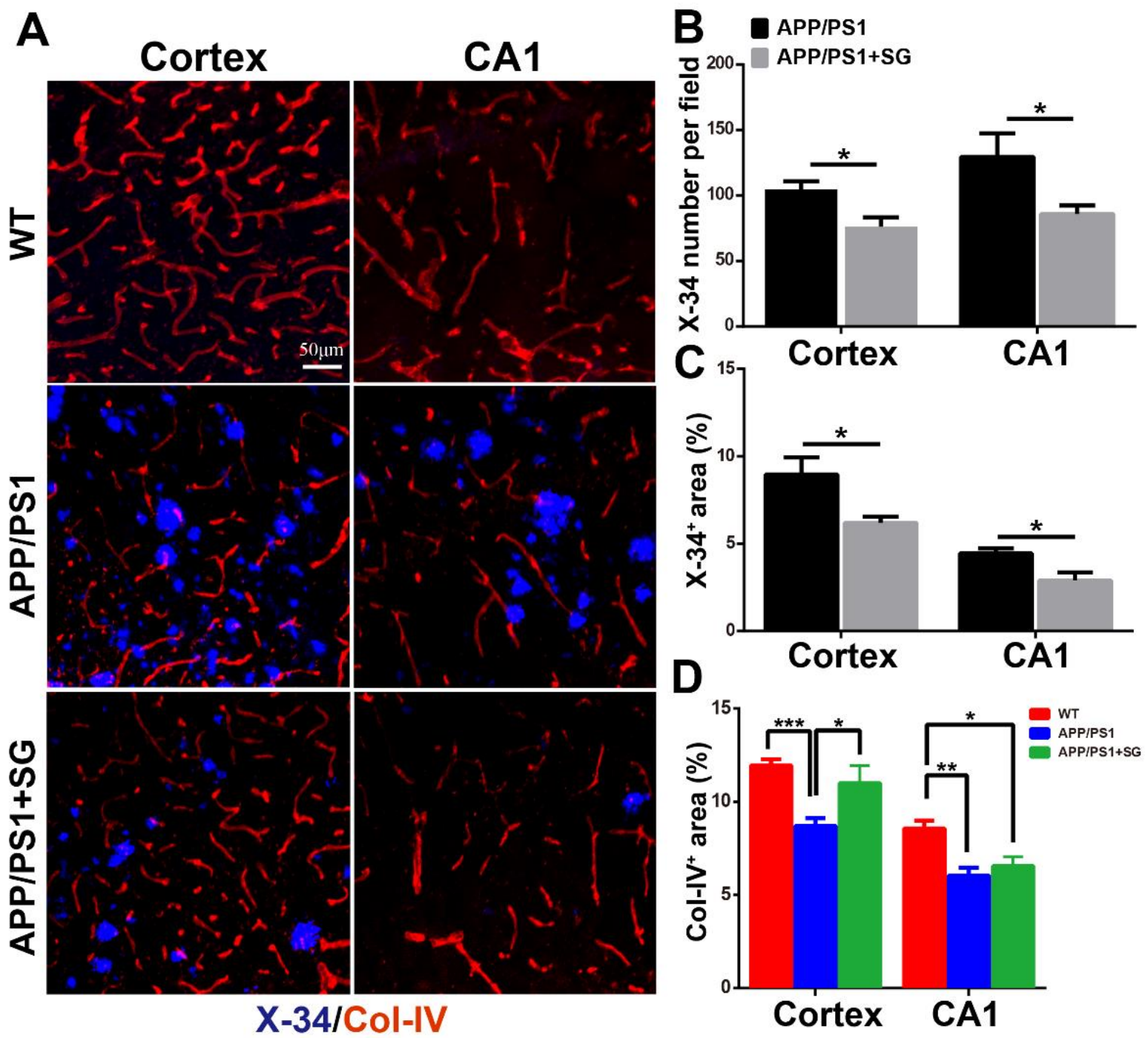

Figure 3. SCF+G-CSF treatment decreases fibrillar A $\beta$ deposits and increases blood vessel density in the brains of aged APP/PS1 mice. (A) Representative confocal images show X-34+ fibrillar A $\beta$ plaques (blue) and collagen IV (Col-IV) immunopositive blood vessels (red) in the cortex and hippocampal CA1 region of aged APP/PS1 mice and age-matched wild type (WT) mice. (B and C) Quantification data show the number of $X-34^{+}$fibrillar A $\beta$ plaques (B) and the percentage of $X$ $34^{+}$fibrillar A $\beta$ area (C) in the cortex and hippocampal CA1 of aged APP/PS1 mice. (D) Quantification data show the percentage of Col-IV ${ }^{+}$area in the cortex and hippocampal CA1 of aged APP/PS1 mice and age-matched WT mice. N=4-5. Mean \pm SEM. $* p<0.05, * * p<0.01, * * * p<0.001$ by Student's t-test $(\mathrm{B}, \mathrm{C})$ or one-way ANOVA followed by Fisher's LSD post hoc test.

Since vascular impairment has been shown to be involved in $\mathrm{A} \beta$ accumulation and $\mathrm{AD}$ progression [42], we then examined the vascular effects of SCF + G-CSF treatment through the analysis of vascular density in the brains of aged APP/PS1 mice. The data showed that the vascular density was decreased in both the cortex $(\mathrm{p}<0.001)$ and hippocampal CA1 $(\mathrm{p}<0.01)$ of aged APP/PS1 mice as compared to the WT controls (Fig. 3D). $\mathrm{SCF}+\mathrm{G}-\mathrm{CSF}$ treatment significantly reversed the vascular loss in the cortex $(\mathrm{p}<0.05)$ of aged APP/PS1 mice, while the treatment did not affect the blood vessel loss in the CA1 region (Fig. 3D).

Altogether, our findings suggest that $\mathrm{SCF}+\mathrm{G}-\mathrm{CSF}$ treatment in aged male APP/PS1 mice leads to remarkable reductions in cerebral $A \beta$ load, which may be the result of increased removal of $A \beta$ deposits in the brain by $\mathrm{SCF}+\mathrm{G}-$ CSF intervention. The SCF+G-CSF-reduced A $\beta$ load may be associated with, but not dependent on, its effects on maintaining vasculature in the brains of aged APP/PS1 mice. 

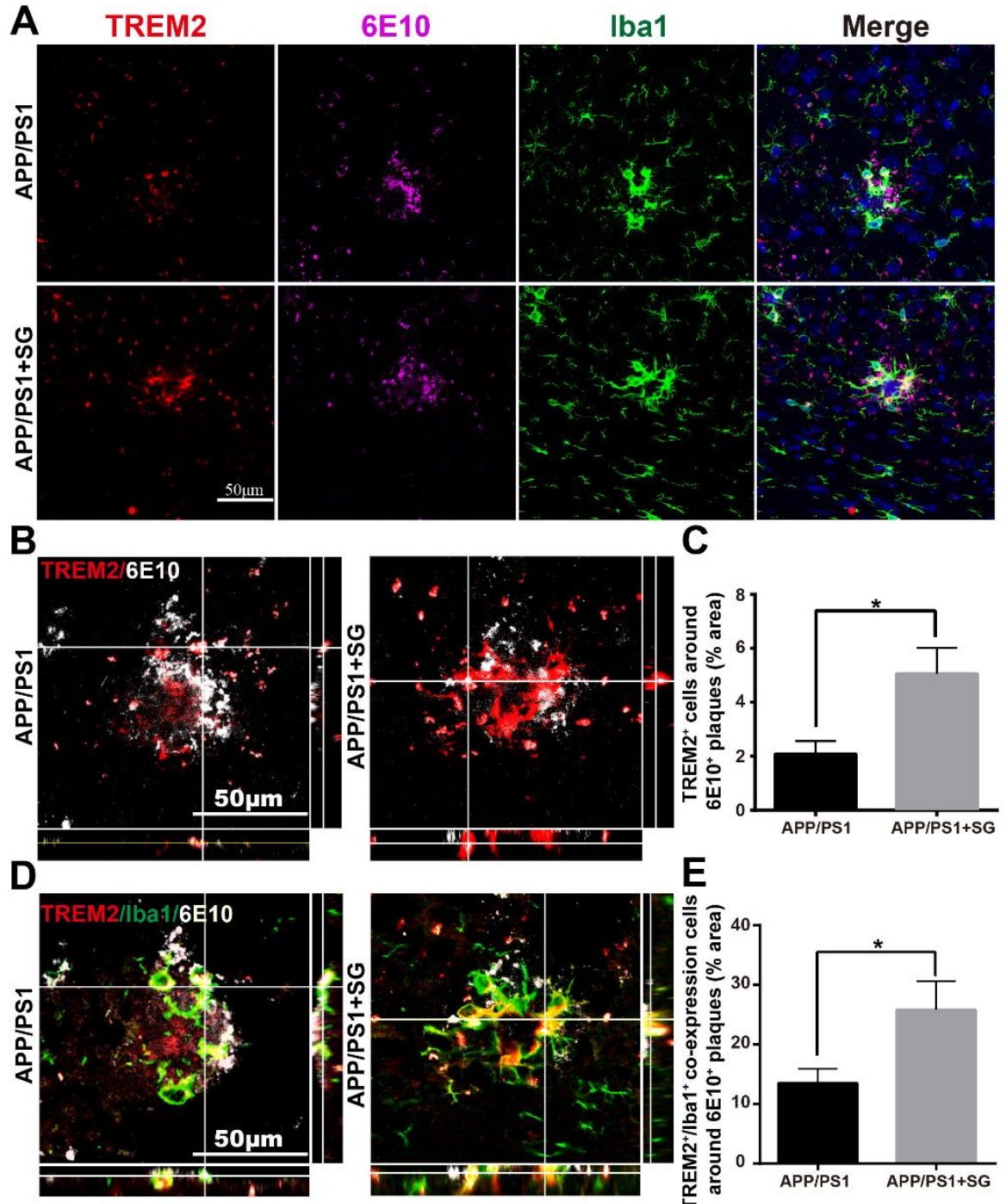

Figure 4. SCF+G-CSF treatment increases TREM2 expression in the $\mathrm{Iba1}^{+}$microglia/macrophages $^{-}$ surrounding the $6 \mathrm{E}^{+} \mathrm{O}^{+}$senile plaques. (A) Representative confocal images of TREM2 (red), 6E10 (purple) and Iba1 (green) triple immunofluorescence staining in the brains of aged APP/PS1 mice. Blue: Nuclear counterstaining by DAPI. (B) Representative orthographic view of z-stack images (12 z-stacks with $1 \mu \mathrm{m}$ intervals) illustrates the location and interaction of TREM $2{ }^{+}$cells (red) and $6 \mathrm{E} 10^{+} \mathrm{A} \beta$ plaques (white) in the brains of aged APP/PS1 mice. (C) Quantification data show the percentage of TREM2+ area surrounding the $6 \mathrm{E} 10^{+} \mathrm{A} \beta$ plaques (within $10 \mu \mathrm{m}$ from the border of the $\mathrm{A} \beta$ plaques) in the brains of aged APP/PS1 mice with or without SCF+G-CSF treatment. (D) Representative orthographic view of zstack images ( $12 \mathrm{z}$-stacks with $1 \mu \mathrm{m}$ intervals) displays the location and interaction of $\mathrm{TREM} 2^{+} / \mathrm{Iba}^{+}$coexpressing cells (yellow) and 6E10 $\mathrm{A} \beta$ plaques (white) in the brains of APP/PS1 mice. (E) Quantification data show the percentage of TREM $2^{+} / \mathrm{Iba} 1^{+}$co-expression area in the total of $\mathrm{Iba}^{+}$area in the vicinity of $6 \mathrm{E} 10^{+} \mathrm{A} \beta$ plaques in the brains of aged APP/PS1 mice with or without SCF+G-CSF treatment. N=4-5. Mean \pm SEM. $* p<0.05$ by Student's t-test.

\section{SCF plus G-CSF treatment increases TREM2 expression in the IbaI ${ }^{+}$cells around the plaques in aged APP/PS1 mice}

Recent studies have demonstrated a vital role of TREM2 in mediating the phagocytosis of $A \beta$ by microglial cells
$[43,44]$. To evaluate whether TREM2 was involved in the increased clearance of $\mathrm{A} \beta$ by $\mathrm{Iba1}^{+}$cells, triple immunofluorescence staining of Iba1, TREM2 and 6E10 was performed in brain sections of APP/PS1 mice. We observed that $\mathrm{SCF}+\mathrm{G}-\mathrm{CSF}$ treatment significantly increased the TREM 2 expression around the $6 \mathrm{E} 10^{+} \mathrm{A} \beta$ 
plaques in the brains of APP/PS1 mice as compared to the vehicle controls $(\mathrm{p}<0.05)$ (Fig. 4A-C) (Supplementary Fig. 2A). Furthermore, the association of $\mathrm{TREM}^{+} / \mathrm{Iba} 1^{+}$ co-expressing cells with $6 \mathrm{E} 10^{+} \mathrm{A} \beta$ plaques was also significantly increased in the SCF+G-CSF-treated APP/PS1 mice as compared to the vehicle controls $(\mathrm{p}<0.05)$ (Fig. 4D and E) (Supplementary Fig. 2B and Supplementary Fig. 3). These data suggest that the increased TREM2 expression in the $\mathrm{Iba}^{+}$ microglia/macrophages might contribute to the enhancement of $A \beta$ clearance in the brains of aged APP/PS1 mice by SCF+G-CSF treatment.
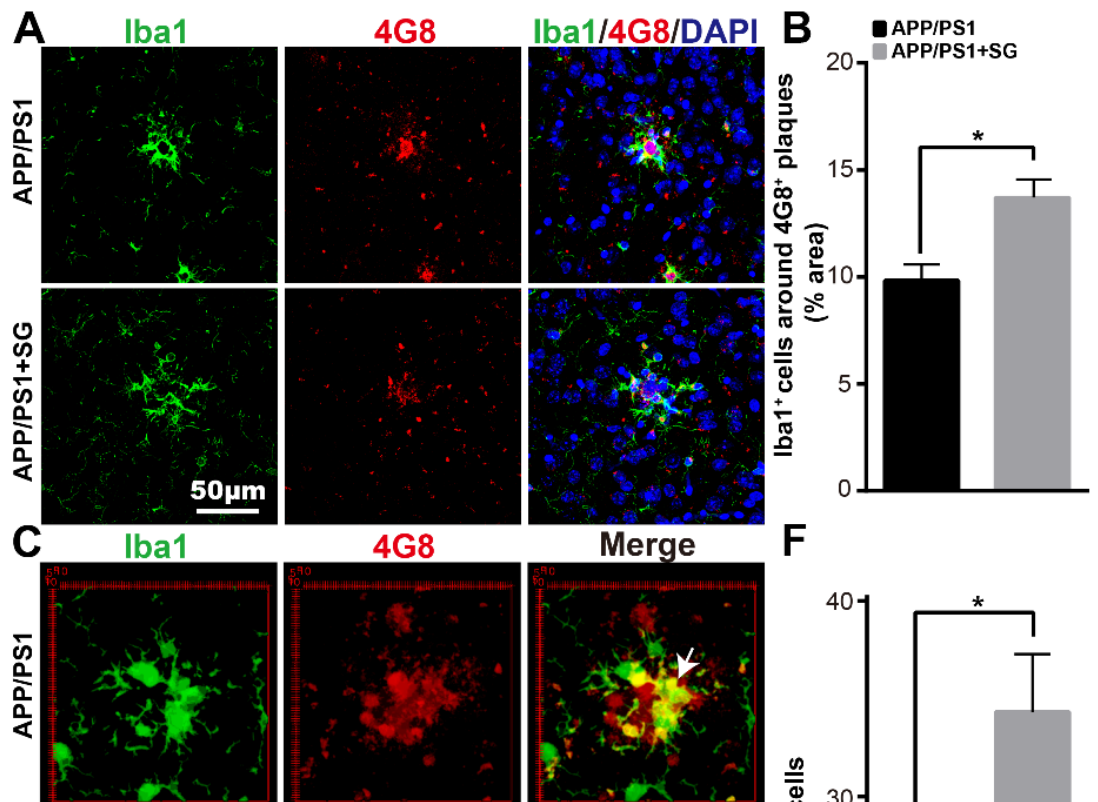

Merge

F
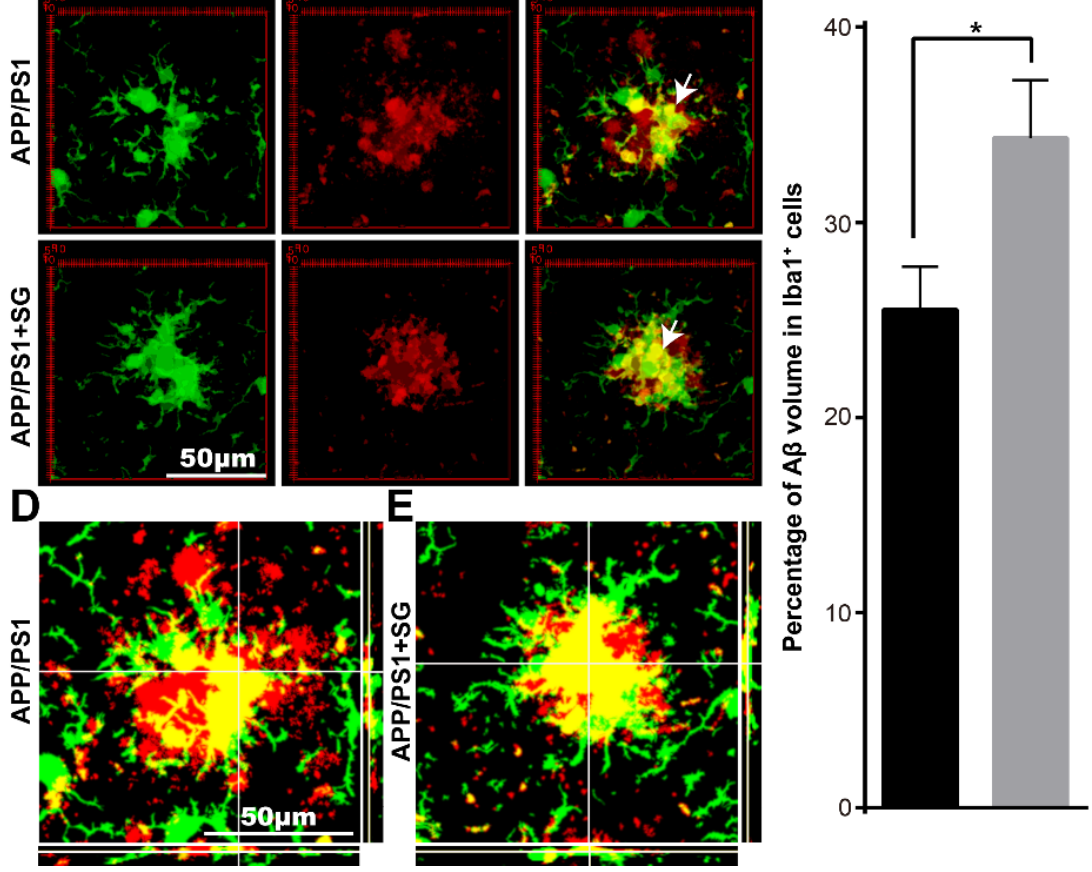

Figure 5. SCF+G-CSF treatment increases the association of $\mathrm{Iba1}^{+}$microglia/macrophages with senile plaques and enhances uptake of $4 \mathrm{Gr}^{+} \mathrm{A} \beta$ by the $\mathrm{Iba1}^{+}$microglia/macrophages in the brains of aged APP/PS1 mice. (A) Representative confocal images illustrate the association of Iba1 ${ }^{+}$cells (green) with $4 \mathrm{G}^{+} \mathrm{A} \beta$ plaques (red) in the brains of aged APP/PS1 mice. Blue: Nuclear counterstaining by DAPI. (B) Quantification of the percentage of $\mathrm{Iba} 1^{+}$area in/surrounding the $4 \mathrm{G} 8^{+} \mathrm{A} \beta$ plaques in the brains of aged APP/PS1 mice with or without SCF+G-CSF treatment. (C) Representative 3dimensional projected images reveal the overlapped (yellow) $\mathrm{Iba}^{+}$cells (green) with $4 \mathrm{G}^{+} \mathrm{A} \beta$ (red) in the brains of aged APP/PS1 mice. The white arrows indicate the co-expression (yellow) of $4 \mathrm{G} 8^{+} \mathrm{A} \beta$ and Iba $1^{+}$cells in the brains of aged APP/PS1 mice. (D and E) Representative orthographic view of zstack images ( $12 \mathrm{z}$-stacks with $1 \mu \mathrm{m}$ intervals) shows the co-expression (yellow) of $4 \mathrm{G}^{+} \mathrm{A} \beta$ (red) and Iba $1^{+}$cells (green) in the brains of aged APP/PS1 mice. (F) Quantification data present the percentage of $4 \mathrm{G}^{+} \mathrm{A} \beta$ volume within the Iba $1^{+}$cells in the brains of aged APP/PS1 mice treated with or without $\mathrm{SCF}+\mathrm{G}-\mathrm{CSF}$. N=4-5. Mean \pm SEM. $* p<0.05$ by Student's t-test. 


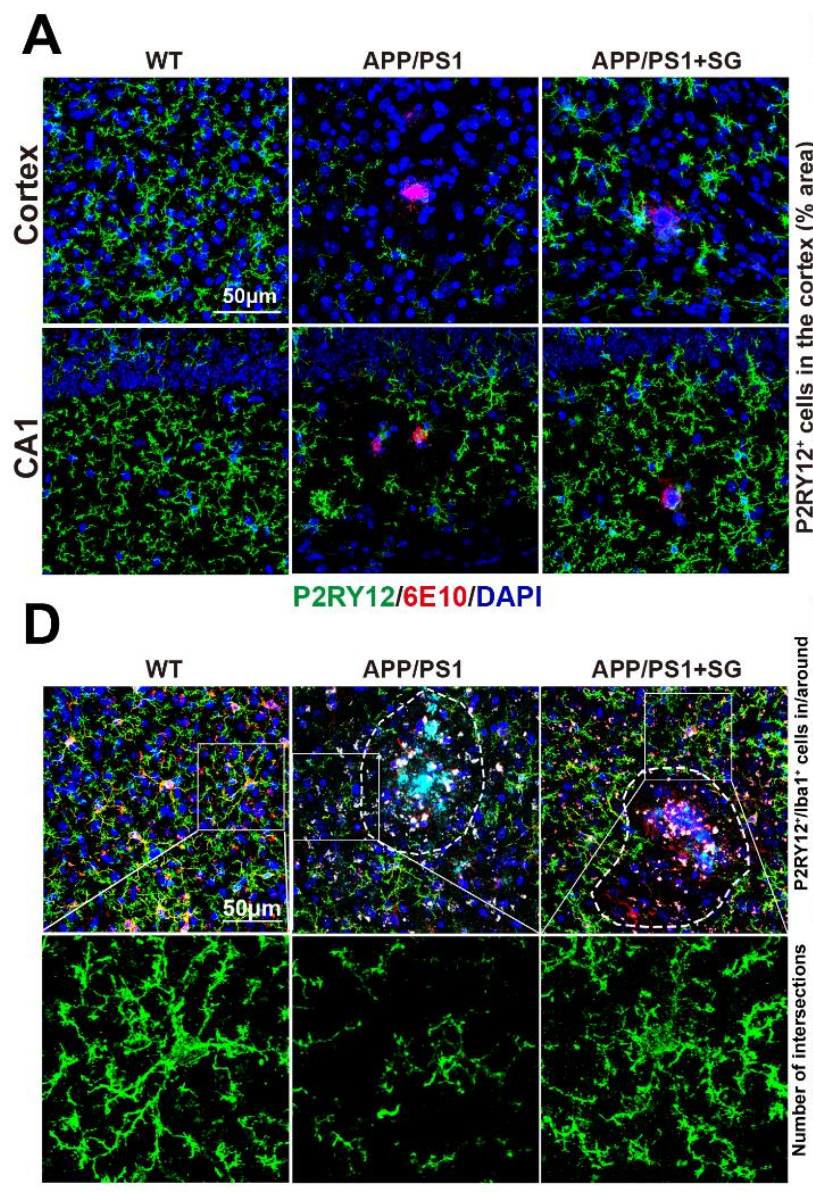

Iba1/P2RY12/6E10/DAPI

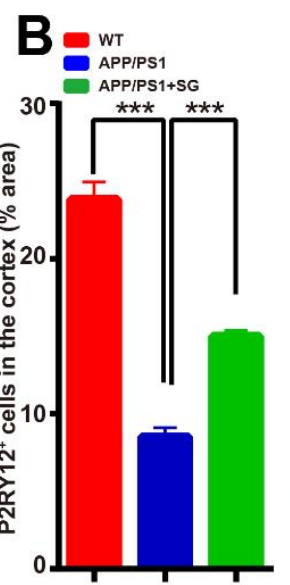

E $=$ APP/PS1
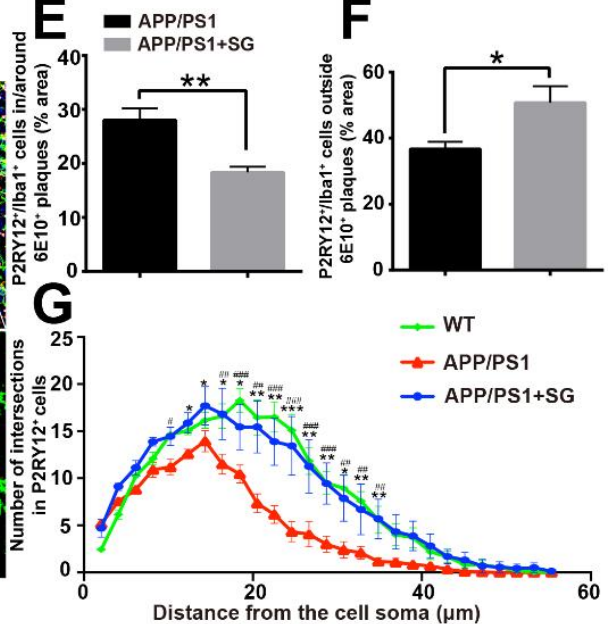

Figure 6. SCF+G-CSF treatment modulates the expression of P2RY12 in the brains of aged APP/PS1 mice. (A) Representative confocal images show P2RY12 (green) and 6E10 (red) double immunofluorescence staining in the cortex and hippocampal CA1 of aged APP/PS1 mice and age-matched wild type (WT) mice. (B and C) Quantification data reveal the percentage of P2RY12+ area in the cortex (B) and CA1 region (C) in aged APP/PS1 mice treated with/without SCF+G-CSF and age-matched WT control mice. N=4-5. Mean \pm SEM. $* * * p<0.001$, one-way ANOVA followed by Fisher's LSD post hoc test. (D) Representative confocal images illustrate the P2RY12 (green) expressing $\mathrm{Iba}^{+}$(red) cells within and outside the $6 \mathrm{E} 10^{+} \mathrm{A} \beta$ plaques (cyan) in the brains of aged APP/PS1 mice and age-matched WT mice. Dash line: separate the area of the vicinity and outside of A $\beta$ plaques. (E) Quantification data show the percentage of $\mathrm{P} 2 \mathrm{RY} 12^{+} / \mathrm{Iba} 1^{+}$co-expressing area within and arround the $6 \mathrm{E} 10^{+} \mathrm{A} \beta$ plaques in the brains of aged APP/PS1 mice treated with or without SCF+G-CSF. (F) Quantification data present the percentage of P2RY $12^{+} / \mathrm{Iba} 1^{+}$ co-expressing area outside the $6 \mathrm{E} 10^{+} \mathrm{A} \beta$ plaques $(10 \mu \mathrm{m}$ away from the border of $\mathrm{A} \beta$ plaques) in the brains of aged APP/PS1 mice treated with or without SCF+G-CSF. N=4-5. Mean \pm SEM. ${ }^{*} p<0.05$, $* * p<0.01$ by Student's t-test. (G) The number of branches in the $\mathrm{P} 2 \mathrm{RY} 12^{+}$microglia outside the $6 \mathrm{E} 10^{+} \mathrm{A} \beta$ plaques is quantified by Sholl analysis. Blue: Nuclear counterstaining by DAPI. N=4-5. Mean \pm SEM. APP/PS1 vs. APP/PS1+SG: $* p<0.05, * * p<0.01, * * * p<0.001$; APP/PS1 vs. WT: \#p<0.05, \#\#p<0.01, \#\#\#p<0.001 by One-way ANOVA followed by Fisher's LSD post hoc test.

\section{SCF plus G-CSF treatment promotes the phagocytosis of Aß by microglia/macrophages in aged APP/PS1 mice}

Next, we sought to examine the effects of SCF+G-CSF treatment in $\mathrm{A} \beta$ removal by microglia/macrophages. To this end, we quantified colocalization of $\mathrm{Iba}^{+}$cells and $\mathrm{A} \beta$ plaques and the volume of engulfed $\mathrm{A} \beta$ in $\mathrm{Iba}^{+}$cells in the brains of APP/PS1 mice using immunofluorescence double staining and confocal imaging. As shown in Figure $5 \mathrm{~A}$ and $\mathrm{B}, \mathrm{SCF}+\mathrm{G}-\mathrm{CSF}$ treatment significantly increased the interaction/association of $\mathrm{Iba1}^{+}$cells with $4 \mathrm{G}^{+}$ plaques $(\mathrm{p}<0.05)$. Moreover, 3-dimensional (3D) analysis revealed that the volume of $4 \mathrm{G}^{+} \mathrm{A} \beta$ within the $\mathrm{Iba} 1^{+}$cells was significantly increased by $\mathrm{SCF}+\mathrm{G}-\mathrm{CSF}$ treatment $(\mathrm{p}<0.05)$ (Fig. 5C- F).

CD68 is a transmembrane glycoprotein and belongs to the family of lysosome-associated membrane proteins and the family of scavenger receptors [45]. CD68 is mainly expressed in lysosomes of microglia and macrophages [46-48] and plays an important role in phagocytizing $A \beta$ [48]. To further validate our findings in Iba1 expressing cells, we quantified the co-localization of 
$4 \mathrm{G}^{+} \mathrm{A} \beta$ with $\mathrm{CD}^{+} 8^{+}$compartment. We found that $\mathrm{CD} 68^{+}$ cells around the $4 \mathrm{G}^{+}$plaques were significantly increased in the cortex of SCF+G-CSF-treated APP/PS1 mice $(\mathrm{p}<0.05)$ (Supplementary Fig. 4A- C). In addition, the colocalization of $4 \mathrm{G}^{+} \mathrm{A} \beta$ in $\mathrm{CD}^{+} 8^{+}$lysosomal compartments was also significantly increased in the cortex of SCF+G-CSF-treated APP/PS1 mice $(\mathrm{p}<0.05)$ (Supplementary Fig. 4D).
These findings demonstrate that $\mathrm{SCF}+\mathrm{G}-\mathrm{CSF}$ treatment enhances the accumulation of $\mathrm{Iba}^{+}$and $\mathrm{CD} 68^{+}$ microglia/macrophages surrounding the senile plaques and promotes phagocytic clearance of $\mathrm{A} \beta$ by the $\mathrm{Iba} 1^{+}$and $\mathrm{CD}^{+} 8^{+}$microglia/macrophages in the brains of aged APP/PS1 mice.

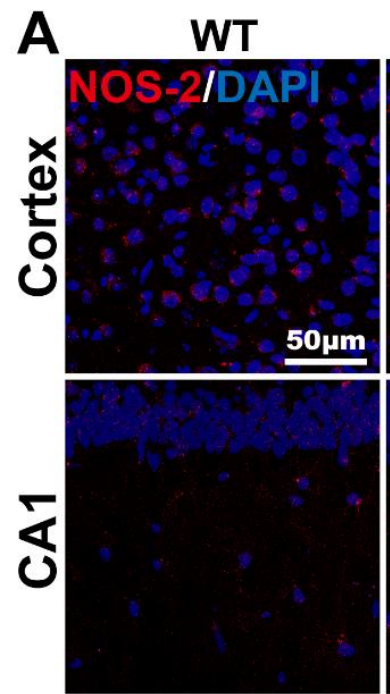

C

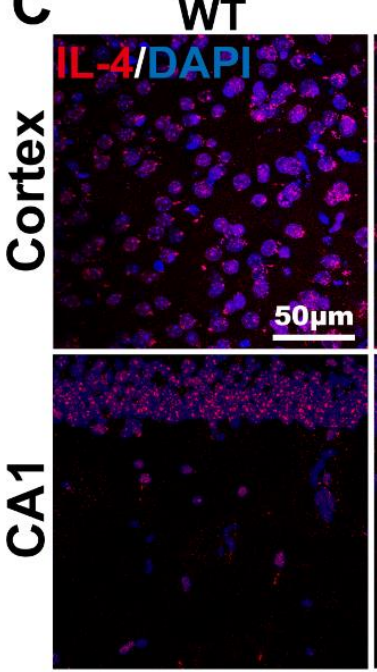

APP/PS1

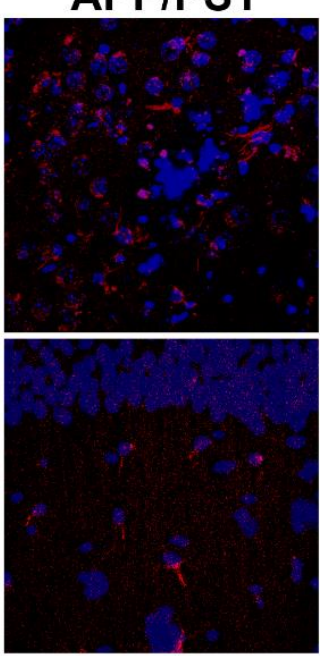

APP/PS1

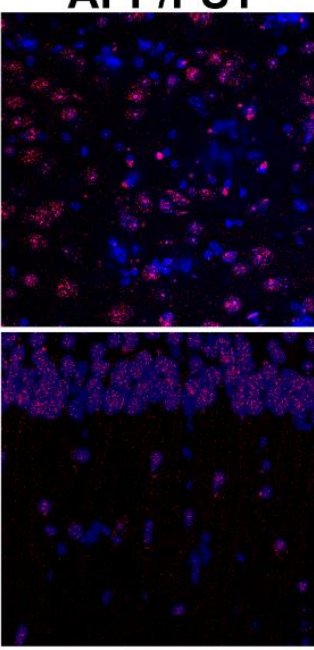

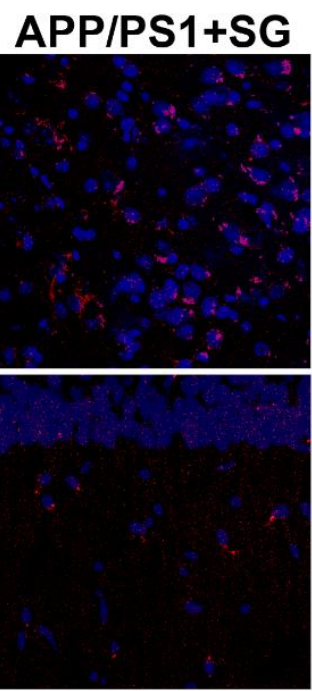

B $=$ wt

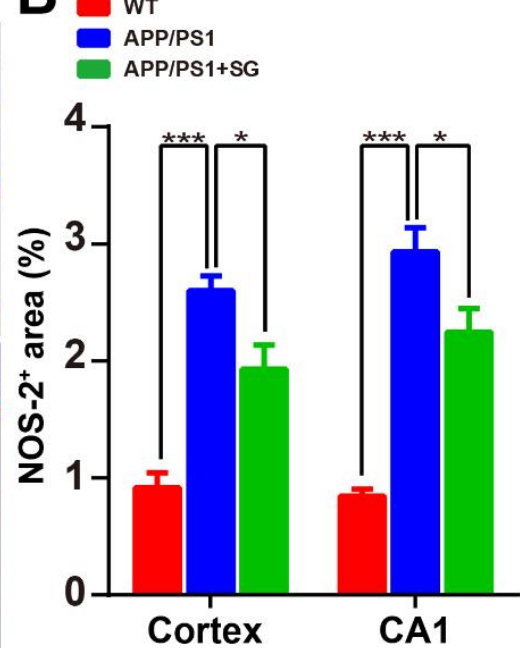

APP/PS1+SG D

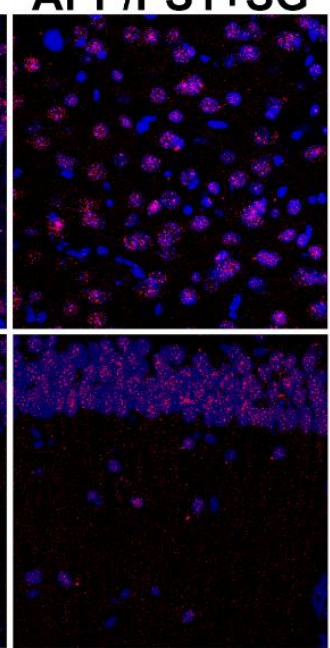

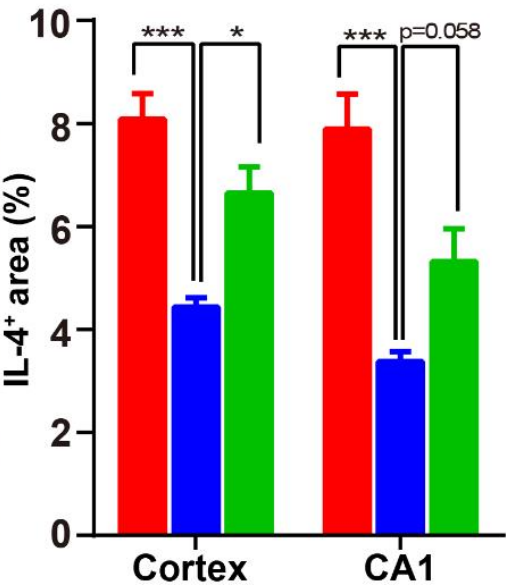

Figure 7. SCF+G-CSF treatment decreases NOS-2 expression and increases IL-4 expression in the brains of aged APP/PS1 mice. (A) Representative confocal images illustrate the NOS-2 immunopositive staining (red) in the cortex and hippocampal CA1 of aged APP/PS1 mice treated with or without SCF+G-CSF and age-matched wild type (WT) mice. (B) Quantification data show the percentage of NOS-2+ area in the cortex and CA1 region of aged APP/PS1mice (with or without SCF+G-CSF treatment) and age-matched WT mice. (C) Representative confocal images illustrate the IL-4 immunopositive staining (red) in the cortex and CA1 region of aged APP/PS1 mice treated with or without SCF+G-CSF and age-matched WT mice. (D) Quantification data show the percentage of $\mathrm{IL}-4^{+}$area in the cortex and CA1 of aged APP/PS1 mice treated with or without SCF+G-CSF and age-matched WT control mice. Blue: Nuclear counterstaining by DAPI. N=4-5. Mean \pm SEM. $* p<0.05$, ***p $<0.001$, one-way ANOVA followed by Fisher's LSD post hoc test. 


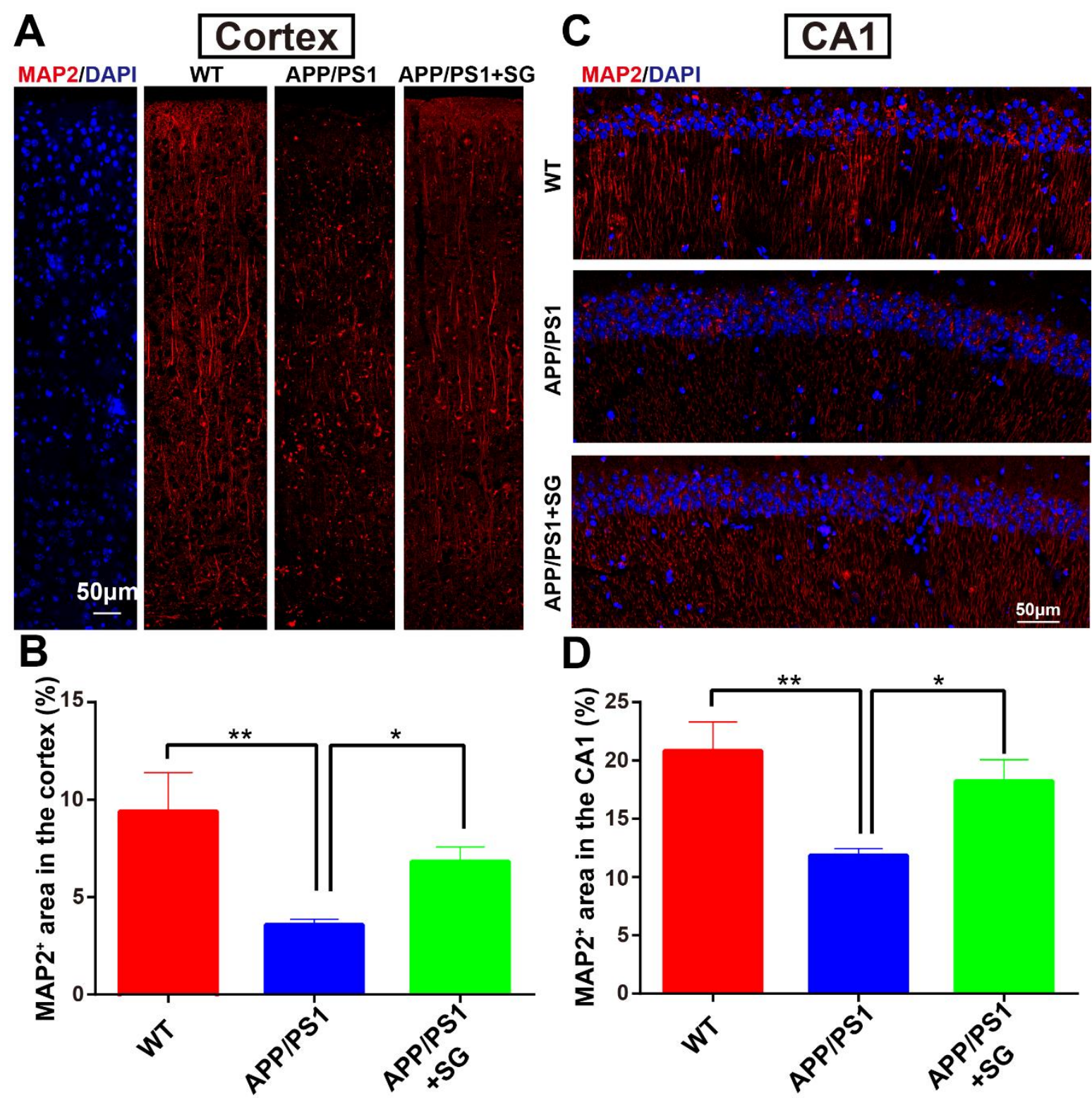

Figure 8. SCF+G-CSF treatment increases dendritic density in the cortex and hippocampus of aged APP/PS1 mice. (A) Representative tile scanning confocal images show MAP2 immunopositive dendrites (red) in the entire cortex of aged APP/PS1 mice treated with/without SCF+G-CSF and age-matched wild type (WT) mice. (B) Quantification data show the changes in the percentage of $\mathrm{MAP2}^{+}$area in the cortex among aged APP/PS1 mice treated with/without SCF+G-CSF and age-matched WT mice. (C) Representative tile scanning confocal images illustrate MAP2 immunopositive dendrites (red) in the CA1 region of aged APP/PS1 mice treated with/without SCF+G-CSF and age-matched WT mice. (D) Quantification data reveal the changes in the percentage of MAP2+ area in the CA1 region among aged APP/PS1 mice treated with/without SCF+G-CSF and age-matched WT mice. Blue: Nuclear counterstaining by DAPI. N=4-5. Mean \pm SEM. * $p<0.05$, ** $*^{*}<0.01$, one-way ANOVA followed by Fisher's LSD post hoc test.

\section{SCF plus G-CSF treatment increases cerebral resting microglial cells in aged APP/PS1 mice}

Long-term microglial activation-induced persistent inflammation in the brain is a significant pathological feature in $\mathrm{AD}[49,50] . \mathrm{P} 2 \mathrm{RY} 12$ is a unique and specific marker expressed in non-activated microglia (also known as homeostatic microglia or resting microglia) that can distinguish the microglial cells from peripheral monocytes/macrophages [51]. Emerging evidence demonstrates that loss/reduction of P2RY12 expression is linked to microglial activation and neuroinflammation $[52,53]$. To identify the interaction between $A \beta$ removal and inflammatory status after $\mathrm{SCF}+\mathrm{G}-\mathrm{CSF}$ treatment, we 
quantified P2RY12 expressing homeostatic microglia in the brains of aged APP/PS1 mice. Our data showed that the P2RY12 expression was significantly decreased in the cortex $(\mathrm{p}<0.001)$ and hippocampal CA1 $(\mathrm{p}<0.001)$ of aged APP/PS1 mice as compared to the WT controls (Fig. 6A-C). Importantly, the reduced P2RY12 expression in the brains of aged APP/PS1 mice was significantly elevated by $\mathrm{SCF}+\mathrm{G}-\mathrm{CSF}$ treatment in both the cortex $(\mathrm{p}<0.001)$ and CA1 ( $\mathrm{p}<0.001)$ (Fig. 6A-C). Interestingly, further analysis revealed that the $\mathrm{P} 2 \mathrm{RY} 12^{+} / \mathrm{Iba}^{+}$resting microglial cells immediately next to the $A \beta$ plaques were significantly decreased in the brains of SCF+G-CSFtreated APP/PS1 mice as compared to the vehicle controls $(\mathrm{p}<0.01)$ (Fig. 6D, E). By contrast, the P2RY12 $/ \mathrm{Iba}^{+}$ resting microglial cells at a distance of $10 \mu \mathrm{m}$ away from the border of $A \beta$ plaques were significantly increased by $\mathrm{SCF}+\mathrm{G}-\mathrm{CSF}$ treatment $(\mathrm{p}<0.05)$ (Fig. 6F). Since the resting microglial cells are characterized by typical small cell bodies with long and thin processes containing multiple branches [54, 55], Sholl analysis was used to quantify the branches of the P2RY $12^{+}$microglia. The data of Sholl analysis demonstrated that the branches of the P2RY12 ${ }^{+}$microglia were significantly decreased in the brains of APP/PS1 mice as compared to the WT controls $(\mathrm{p}<0.05) . \mathrm{SCF}+\mathrm{G}-\mathrm{CSF}$ treatment significantly increased the branches of the P2RY12 ${ }^{+}$microglia in the brains of APP/PS1 mice as compared to the vehicle control APP/PS1 mice $(p<0.05)$ (Fig. 6G).

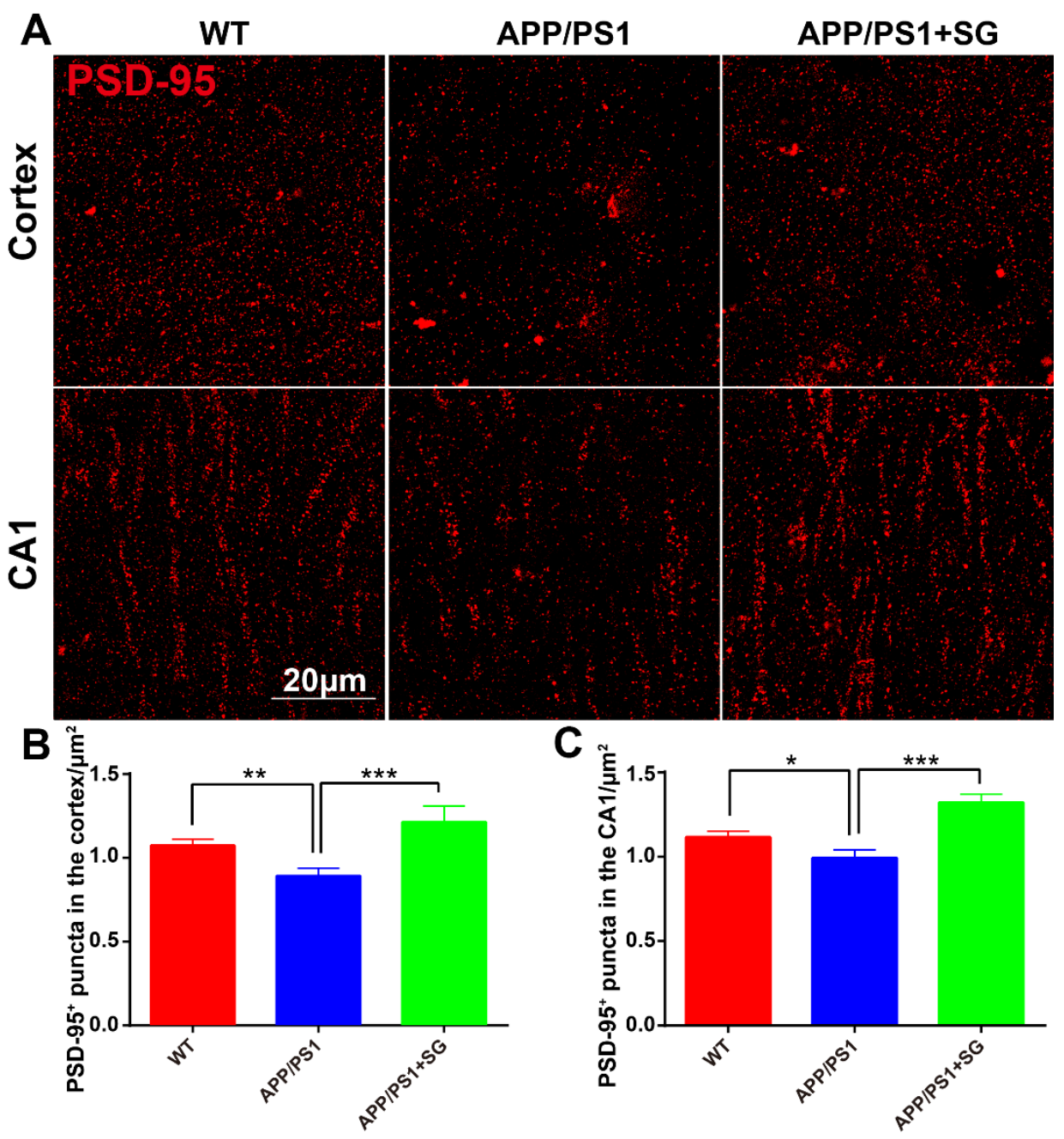

Figure 9. SCF+G-CSF treatment increases PSD-95 positive post-synapses in the cortex and hippocampus of aged APP/PS1 mice. (A) Representative confocal images show PSD-95 immunopositive puncta (red) in the cortex and hippocampal CA1 of aged APP/PS1 mice treated with/without SCF+G-CSF and age-matched wild type (WT) mice. (B and C) Quantification data show the changes of PSD- $95^{+}$puncta in the cortex (B) and hippocampal CA1 (C) among aged APP/PS1 mice treated with/without SCF+G-CSF and age-matched WT mice. N=4-5. Mean \pm SEM. * $p<0.05$, $* * p<0.01, * * * p<0.001$, one-way ANOVA followed by Fisher's LSD post hoc test. 
To further verify the contribution of $\mathrm{SCF}+\mathrm{G}-\mathrm{CSF}$ treatment in maintaining/restoring the homeostatic state of microglia, we used another homeostatic microglial marker, TMEM119, to detect the homeostatic microglia. We observed that the expression of TMEM119 in the cortex of APP/PS1 mice was significantly decreased as compared to the WT mice $(p<0.001)$ (Supplementary Fig. 5A, B). SCF+G-CSF- treated APP/PS1 mice showed a trend toward increasing TMEM119 positive microglia in the cortex when compared to the vehicle control APP/PS1 mice $(\mathrm{p}=0.053)$ (Supplementary Fig. 5B). In the cortical area at a distance of $15 \mu \mathrm{m}$ away from the border of $\mathrm{A} \beta$ plaques, TMEM119 positive microglial cells were significantly increased by SCF+G-CSF treatment $(\mathrm{p}<0.05)$ (Supplementary Fig. 5C).

These findings demonstrate that $\mathrm{SCF}+\mathrm{G}-\mathrm{CSF}$ treatment leads to increases in microglial homeostasis in the brains of aged APP/PS1 mice.

SCF plus G-CSF treatment decreases NOS-2 and increases $I L-4$ expression in the brains of aged APP/PSI mice
To further evaluate the effects of SCF+G-CSF intervention on the inflammatory reactivity in the brains of aged APP/PS1 mice, we quantified the expression of pro-inflammation factor, NOS-2, and anti-inflammation factor, IL-4, in the brains of aged APP/PS1 mice through immunohistochemistry. We observed that the expression of NOS-2 was significantly increased in both the cortex $(p<0.001)$ and hippocampal CA1 region $(p<0.001)$ of aged APP/PS1 mice as compare to the WT controls (Fig. 7A, B). SCF+G-CSF treatment significantly decreased the NOS-2 expression in both the cortex $(\mathrm{p}<0.05)$ and CA1 region $(\mathrm{p}<0.05)$ of aged APP/PS1 mice (Fig. 7A, B). Furthermore, in comparison with the WT controls, the aged APP/PS1 mice in the vehicle control group showed significant decreases of IL-4 expression in both the cortex $(\mathrm{p}<0.001)$ and CA1 region ( $\mathrm{p}<0.001)$ (Fig. 7C and D). In the SCF+G-CSF-treated aged APP/PS1 mice, however, the IL-4 expression was elevated in the cortex $(\mathrm{p}<0.05)$ and $\mathrm{CA} 1$ region $(\mathrm{p}=0.058)$ as compared to the vehicle controls (Fig. 7C and D). These results further confirm the contribution of SCF+G-CSF treatment in modulating the inflammatory status in the brains of aged male APP/PS1 mice.

A $_{\text {P2RY12 }^{+} \text {and X-34+ area correlation in the cortex }}$ C

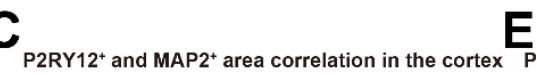

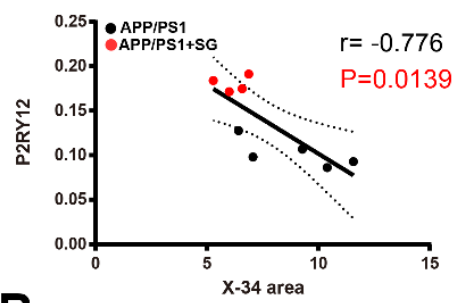

B

$\mathrm{P} 2 \mathrm{RY} 12^{+}$and $\mathrm{X}-34^{+}$area correlation in the CA1

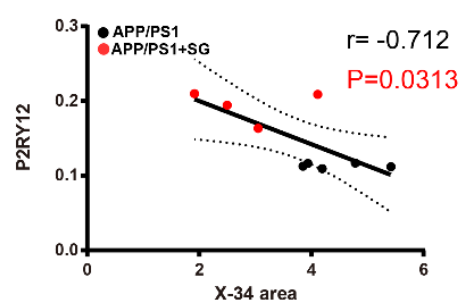

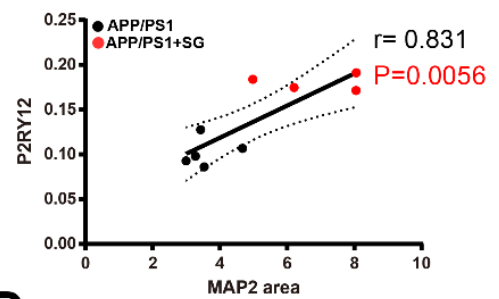

D

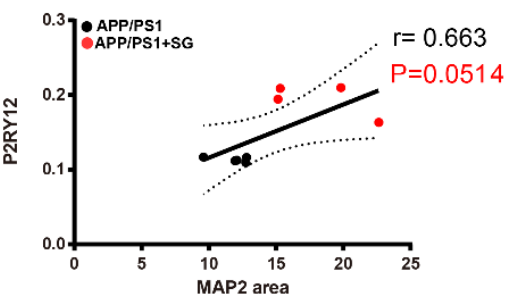

P2RY12+ and PSD-95+ puncta correlation in the cortex

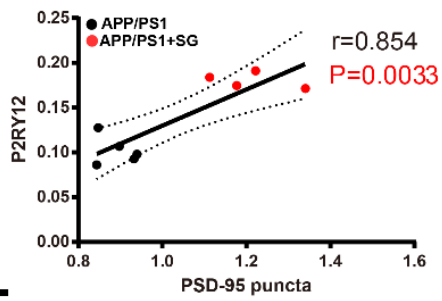

$\mathbf{F}$

$\mathrm{P}^{2} \mathrm{RY} 12^{+}$and PSD $-95^{+}$puncta correlation in the CA1

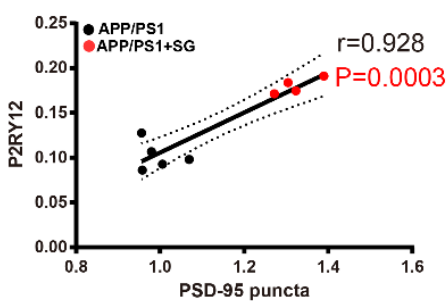

Figure 10. Correlation between A $\beta$ plaques, homeostatic microglia, dendrites and synapses in the brains of aged APP/PS1 mice treated with or without SCF+G-CSF. (A and B) P2RY12+ homeostatic microglia show a significantly negative correlation with X-34+ fibrillar A $\beta$ plaques in the cortex $(r=-0.776, p<0.05)(A)$ and hippocampal CA1 $(r=-0.712, p<0.05)$ (B). Note that increased $\mathrm{P} 2 \mathrm{RY} 12^{+}$resting microglia are correlated with the reduced $\mathrm{X}-34^{+}$fibrillar $\mathrm{A} \beta$ plaques in the cortex and hippocampal CA1 in the SCF+G-CSF-treated aged APP/PS1 mice. (C and D) P2RY12+ microglia display a positive correlation with MAP2 ${ }^{+}$dendrites in the cortex $(r=0.831, \mathrm{p}<0.01)(\mathrm{C})$ and hippocampal CA1 $(\mathrm{r}=0.663, \mathrm{p}=0.051)$ (D). Note that increased $\mathrm{P} 2 \mathrm{RY} 12^{+}$homeostatic microglia are correlated with the increased MAP2 ${ }^{+}$dendrites in the cortex and CA1 in the SCF+G-CSFtreated aged APP/PS1 mice. (E and F) P2RY12 ${ }^{+}$microglia show a significantly positive correlation with PSD-95 ${ }^{+}$puncta in the cortex $(\mathrm{r}=0.854, \mathrm{p}<0.01)$ (E) and hippocampal CA1 $(\mathrm{r}=0.928, \mathrm{p}<0.001)(\mathrm{F})$. Note that the increased P2RY12+ homeostatic microglia are correlated with the increased PSD- $95^{+}$puncta in the cortex and CA1 in the SCF+G-CSF-treated aged APP/PS1 mice. 
To explore the cell type expression of NOS-2 and IL-4 in the WT and APP/PS1 mice, we performed double immunofluorescence staining of NOS-2 and IL-4 with NeuN (neuronal marker), Iba1 (microglial marker) and GFAP (astrocyte marker). We observed that NOS-2 was expressed in the neurons $\left(\mathrm{NeuN}^{+}\right)$(Supplementary Fig. 6A) and microglia $\left(\mathrm{Iba1}^{+}\right.$) (Supplementary Fig. 6B) in both aged WT and APP/PS1 mice, but no obvious expression was seen in the astrocytes $\left(\mathrm{GFAP}^{+}\right)$ (Supplementary Fig. 6C). IL-4 was expressed in the neurons $\left(\mathrm{NeuN}^{+}\right)$(Supplementary Fig. 7A), microglia $\left(\mathrm{Iba1}^{+}\right)$(Supplementary Fig. 7B) and astrocytes $\left(\mathrm{GFAP}^{+}\right)$ (Supplementary Fig. 7C) in both aged WT and APP/PS1 mice.

\section{SCF plus G-CSF treatment reverses the loss of cerebral dendrites and synapses in aged APP/PS1 mice}

Dendritic degeneration and synaptic loss induced by $A \beta$ neurotoxicity and chronic inflammation are the major causes for the cognitive impairments in AD [56-58]. Building on our findings that $\mathrm{SCF}+\mathrm{G}-\mathrm{CSF}$ treatment enhanced the $\mathrm{A} \beta$ removal and ameliorated the inflammatory status, we then sought to determine the efficacy of SCF+G-CSF treatment in remodeling dendrites and synapses in aged APP/PS1 mice. As shown in Figure 8, $\mathrm{MAP}^{+}$dendrites were significantly decreased in both the entire cortex $(\mathrm{p}<0.01)$ (Fig. 8A, B) and hippocampal CA1 region $(\mathrm{p}<0.01)$ (Fig. $8 \mathrm{C}, \mathrm{D})$ of aged APP/PS1 mice as compared to the WT controls. The reduced $\mathrm{MAP}^{+}$dendrites in the brains of aged APP/PS1 mice were significantly restored by $\mathrm{SCF}+\mathrm{G}-\mathrm{CSF}$ intervention in both the entire cortex $(\mathrm{p}<0.05)$ (Fig. 8A, B) and CA1 region $(\mathrm{p}<0.05)$ (Fig. 8C, D). Furthermore, PSD-95 (a post-synaptic marker) positive puncta were significantly decreased in both the cortex $(\mathrm{p}<0.01)$ (Fig. 9A, B) and CA1 region ( $<<0.05)$ (Fig. 9A, C) of the aged APP/PS1 mice as compared to the WT controls. SCF+GCSF treatment completely prevented the loss of PSD-95 ${ }^{+}$ puncta in both the cortex ( $\mathrm{p}<0.001)$ (Fig. 9A, B) and CA1 region ( $\mathrm{p}<0.001$ ) (Fig. 9A, C) of aged APP/PS1 mice as compared to the vehicle controls. These data suggest that $\mathrm{SCF}+\mathrm{G}-\mathrm{CSF}$ treatment reverses the loss of cerebral dendrites and synapses in aged APP/PS1.

A recent study has revealed that neurofibrillary pathology occurs in the brain of 12-24-month-old APPswe/PS1dE9 (APP/PS1) mice [59]. To determine the effects of SCF+G-CSF treatment on tau pathology in aged APP/PS1 mice, we used the AT8, a tau phosphorylation (Ser202, Thr205) antibody, to probe tangle-like structures in 26 27-month-old APP/PS1 mice. We observed apparent aggregated $\mathrm{AT}^{+}$tau pathological structures in the cortex of APP/PS1 mice (Supplementary Fig. 8A). The number of tau pathological structures (AT8 ${ }^{+}$puncta) was not significantly different between SCF+G-CSFtreated and vehicle control APP/PS1 mice (Supplementary Fig. 8B and C). However, SCF+G-CSFtreated APP/PS1 mice showed significant reductions in the average size of $\mathrm{AT}^{+}$puncta in the cortex as compared to the vehicle control APP/PS1 mice $(p<0.001)$ (Supplementary Fig. 8D). This observation indicates that SCF+G-CSF treatment ameliorates tau pathology in aged APP/PS1 mice.

\section{Correlation between Aß plaques, homeostatic microglia, dendrites and synapses}

To further determine the interaction between $A \beta$ plaque load and the quantity of resting microglia, dendrites and synapses, we performed a correlation analysis in both the vehicle controls and $\mathrm{SCF}+\mathrm{G}-\mathrm{CSF}$-treated aged APP/PS1 mice. The data revealed that a significantly negative correlation was seen between $\mathrm{P} 2 \mathrm{RY} 12^{+}$resting microglia and $\mathrm{X}-34^{+}$fibrillar $\mathrm{A} \beta$ plaques in both the cortex $(\mathrm{r}=-$ 0.776, $\mathrm{p}<0.05$ ) (Fig. 10A) and hippocampal CA1 ( $\mathrm{r}=$ $0.712, \mathrm{p}<0.05$ ) (Fig. 10B) of the APP/PS1 mice. These data suggest that the areas with high $A \beta$ plaque deposits show less expression of $\mathrm{P} 2 \mathrm{RY} 12^{+}$resting microglia, while the areas with reduced $A \beta$ plaque deposits display increased $\mathrm{P} 2 \mathrm{RY} 12^{+}$resting microglia. This observation indicates that $\mathrm{A} \beta$ deposits lead to loss of $\mathrm{P} 2 \mathrm{RY} 12^{+}$resting microglia.

However, a positive correlation was found between $\mathrm{P} 2 \mathrm{RY} 12^{+}$microglia and $\mathrm{MAP}^{+}$dendrites in the cortex $(\mathrm{r}=0.831, \mathrm{p}<0.01)$ (Fig. 10C) and hippocampal CA1 $(\mathrm{r}=0.663, \mathrm{p}=0.0541)$ of the APP/PS1 mice (Fig. 10D). Furthermore, there was a significantly positive correlation between P2RY $12^{+}$microglia and PSD- $95^{+}$puncta in both the cortex $(\mathrm{r}=0.854, \mathrm{p}<0.01)$ (Fig. 10E) and hippocampal CA1 ( $r=0.928, p<0.001)$ (Fig. 10F) of the APP/PS1 mice. These findings demonstrate that the microenvironment with increased $\mathrm{P} 2 \mathrm{RY} 12^{+}$resting microglia/homeostatic microglia is beneficial to maintain dendrites and synapses in the brain of aged APP/PS1 mice.

\section{DISCUSSION}

Using a widely-used mouse model of cerebral amyloidosis in $\mathrm{AD}$ research, the present study has demonstrated the therapeutic efficacy of combined SCF and G-CSF treatment in aged male APP/PS1 mice. Our data have revealed that $\mathrm{SCF}+\mathrm{G}-\mathrm{CSF}$ treatment reduces diffuse and fibrillar $A \beta$ deposits, increases the association of microglia/macrophages with senile plaques, and enhances $A \beta$ uptake by microglia/macrophages in the brains of aged APP/PS1 mice. Furthermore, SCF+G-CSF treatment increases homeostatic microglia and ameliorates inflammatory status in the brains of aged 
APP/PS1 mice. Systemic administration of SCF+G-CSF also reverses the loss of dendrites and synapses and reduces pathological tau in the brains of aged APP/PS1 mice. These data suggest that $\mathrm{SCF}+\mathrm{G}-\mathrm{CSF}$ treatment ameliorates the pathological severity in the brain of aged APP/PS1 mice.

Microglia are the resident macrophages in the central nervous system. Microglial cells constantly survey their local microenvironment, control neurogenesis and synaptic generation, and contribute to the maintenance of brain homeostasis. Microglia also detect the first signs of pathogenic invasion and tissue damage and support tissue repair [60]. Iba1 is the marker to detect both resting and active microglia in the brains of $\mathrm{AD}$ patients and mouse models of AD [32, 61, 62]. Many other markers have been used to identify specific phenotypes of microglia. Recent transcriptomic studies have revealed that homeostatic microglia gradually adopt a unique phenotype of phagocytic disease-associated microglia (DAM) in the brains of amyloidogenic mouse models and AD patients [62-64]. Progressive A $\beta$ accumulation accelerates DAM formation [64]. DAM phenotype is characterized by downregulation of key homeostatic genes including P2ry12, Cx3cr1 and Tmem119 and upregulation of ADassociated genes (e.g. Trem2, ApoE, CD68) [62, 63]. The location of DAM is revealed in the vicinity of the $A \beta$ plaques in both mouse models and $\mathrm{AD}$ patients $[62,63$, $65,66]$. Whether the activated microglia (DAM) play a beneficial role, detrimental role or both in $\mathrm{AD}$ progression remains to be clarified [67]. It is also not clear the underlying mechanism of microglial phenotype switch during disease progression and why DAM clusters concentrate in the area of $A \beta$ plaques. Emerging evidence shows that fibrillar $A \beta$ is the main driver for switching microglia to DAM phenotype [68]. Deleting ApoE or Trem 2 blocks microglial accumulation around $A \beta$ plaques $[64,69]$. It has been shown that DAM around $A \beta$ plaques are phagocytic cells to phagocytize $A \beta$ [62]. These findings suggest that DAM accumulation in the area of $A \beta$ plaques may be involved in limiting $A \beta$ accumulation.

Hematopoietic growth factors have been demonstrated to effectively reduce $A \beta$ load in the brains of APP/PS1 mice. In addition to SCF and G-CSF, macrophage colony-stimulating factor (M-CSF) and granulocyte-macrophage colony-stimulating factor (GMCSF) are also the family members of hematopoietic growth factors. Systemic injection of M-CSF [70] or GMCSF [71] to APP/PS1 mice results in decreases of cerebral $\mathrm{A} \beta$ deposits. An in vitro study reveals that M-CSF treatment increases microglial proliferation and phagocytosis of $\mathrm{A} \beta$ in primary cultured adult human microglia [72]. In a previous study, we have demonstrated that subcutaneous administration of SCF+G-CSF in 9month-old APP/PS1 mice results in reduced $A \beta$ load at the age of 18 months, indicating a long-term beneficial effect of SCF+G-CSF in inhibiting $A \beta$ accumulation [32]. It has been reported that subcutaneous injections of GCSF alone in 7-9 or 13-15 month-old APP/PS1 mice lead to $A \beta$ reduction in 3 weeks [73], while clinical evidence reveals no effect on reducing $A \beta$ load by G-CSF alone treatment [74]. In a long-term study, we have observed that SCF+G-CSF combination treatment in 10-month-old APP/PS1 mice shows more effective and stable effects in reducing $\mathrm{A} \beta$ load as compared to $\mathrm{G}-\mathrm{CSF}$ or $\mathrm{SCF}$ alone ( $\mathrm{Li}$ et al., unpublished observations). In addition to the beneficial effects observed in middle-aged APP/PS1mice, the present study has revealed that subcutaneous administration of SCF+G-CSF at an elderly age $(\sim 25$ months old) reduces the burden of both fibrillar $A \beta$ and diffuse $A \beta$ in the APP/PS1 mice.

Although the precise mechanism underlying the $\mathrm{SCF}+\mathrm{G}-\mathrm{CSF}-$ reduced $\mathrm{A} \beta$ load remains unclear, our data suggest that increasing phagocytic removal of $A \beta$ by microglia/macrophages is involved in the SCF+G-CSFreduced A $\beta$ load in the brain of aged APP/PS1 mice. Both resident $\mathrm{Iba}^{+}{ }^{+}$microglia and bone marrow-derived Iba ${ }^{+}$ macrophages have been proposed to be involved in the clearance of $A \beta[32,72,75,76]$. As it is hard to unambiguously distinguish these cellular populations, their individual contribution to $\mathrm{A} \beta$ clearance in $\mathrm{AD}$ is not entirely clear. In the present study, we have revealed that the engulfed $4 \mathrm{G}^{+} \mathrm{A} \beta$ in the $\mathrm{Iba} 1^{+}$microglia/macrophages is increased by SCF+G-CSF treatment. CD68 is the marker for detecting lysosomes of microglia and macrophages [46-48]. Our data have also demonstrated that the colocalization of $4 \mathrm{G}^{+} \mathrm{A} \beta$ in $\mathrm{CD} 68^{+}$lysosomes of microglia/macrophages is increased by $\mathrm{SCF}+\mathrm{G}-\mathrm{CSF}$ treatment in aged APP/PS1 mice. These findings suggest that $\mathrm{SCF}+\mathrm{G}-\mathrm{CSF}$ treatment-reduced $\mathrm{A} \beta$ load in the brains of aged APP/PS1 mice is modulated by enhanced $A \beta$ uptake and degradation (A $\beta$ clearance) through phagocytosis by microglia/macrophages. Similar findings have been reported in the M-CSF study showing that Iba $1^{+}$microglia-internalized A $\beta$ in the brain of APP/PS1 mice is increased by systemic injection of M-CSF [70]. An in vitro study also demonstrates the efficacy of M-CSF in enhancing the ability of microglia to phagocytize and degrade fibrillar $\mathrm{A} \beta$ [76].

Recent studies have demonstrated that TREM2 plays a vital role in mediating phagocytosis and degradation of $\mathrm{A} \beta$ by $\mathrm{Iba}^{+}$microglia/macrophages in transgenic mouse models of $\mathrm{AD}[43,44]$. Loss of function mutation in TREM2 (p.R47H) has been shown to be associated with an increased risk of $\mathrm{AD}[77,78]$. It has been documented that TREM2 plays a critical role in governing microglial cell activation, driving DAM phenotype, and promoting microglial cell accumulation around $A \beta$ plaques $[69,79]$. Our data have revealed that 
TREM2 is mainly expressed in the Iba $1^{+}$ microglia/macrophages surrounding the $A \beta$ plaques, while TREM 2 could not be detected in the Iba $1^{+}$cells distant from the plaques in the brains of APP/PS1 mice. This observation is in line with the findings reported by other investigators [80]. The findings of the present study have also uncovered that $\mathrm{SCF}+\mathrm{G}-\mathrm{CSF}$ treatment increases TREM 2 expression in the Iba $1^{+}$microglia/macrophages surrounding the senile plaques, suggesting that TREM2 upregulation is involved in SCF+G-CSF-enhanced $A \beta$ clearance by the $\mathrm{Iba1}^{+}$microglia/macrophages in the senile plaques. In addition to SCF+G-CSF-increased TREM 2 expression in the Iba $1^{+}$microglia/macrophages surrounding the $\mathrm{A} \beta$ plaques and $\mathrm{SCF}+\mathrm{G}-\mathrm{CSF}$-increased CD68-expressing microglia/ macrophages around the $\mathrm{A} \beta$ plaques, it is worth noting that $\mathrm{SCF}+\mathrm{G}-\mathrm{CSF}$ treatment also leads to reduced $\mathrm{P} 2 \mathrm{RY} 12^{+} / \mathrm{Iba}^{+}$homeostatic microglia in the vicinity of the $\mathrm{A} \beta$ plaques. Our observations suggest that SCF+G-CSF treatment in aged APP/PS1 mice enhances the transformation of homeostatic microglia into phagocytic DAM phenotype in the area next to the $A \beta$ plaques. This $\mathrm{SCF}+\mathrm{G}-\mathrm{CSF}-$ enhanced microglial phenotype transformation occurring particularly at the location surrounding the $A \beta$ plaques may be necessary to reinforce $A \beta$ removal and restrict $A \beta$ induced pathology. A recent transcriptomic study has shown that the population of DAM contains both proinflammatory DAM and anti-inflammatory DAM. The anti-inflammatory DAM express phagocytic genes. Using a pharmacological approach to promote antiinflammatory DAM or inhibit pro-inflammatory DAM leads to enhanced $\mathrm{A} \beta$ clearance in $5 \mathrm{xFAD}$ mice [81]. It would be an interesting question to be addressed in future studies whether promoting anti-inflammatory DAM transformation is involved in the SCF+G-CSF-enhanced $\mathrm{A} \beta$ clearance in the brains of aged APP/PS1 mice.

As stated earlier, resident microglia play a vital role in the maintenance of brain homeostasis. Losing the homeostatic phenotype in microglia is thought to be linked to pathological severity in the context of $\mathrm{AD}[65$, 67]. P2RY12 is a specific marker for detecting the homeostatic/resting microglia in the brain [51, 53, 82]. P2RY12 is also a purinergic receptor which plays a key role in maintaining homeostatic microglia [67]. In addition to accumulation of DAM around the amyloid plaques, reduced $\mathrm{P} 2 \mathrm{RY} 12^{+}$microglia have been found in the cerebral parenchyma in mouse models and $\mathrm{AD}$ patients [66, 67]. In agreement with these findings reported by others, the data of the present study have revealed a large reduction of $\mathrm{P} 2 \mathrm{RY} 12^{+}$microglia in both the cortex and hippocampus of aged APP/PS1 mice. While the consequences of P2RY12 downregulation in $\mathrm{AD}$ are not fully understood, P2RY12 expression in microglia has been proposed to have protective effects in the context of $\mathrm{AD}$ [67]. In the cerebral cortex of $\mathrm{AD}$ patients, reductions of P2RY12 immunoreactivity are correlated with neuropathological scores and synaptic loss [83]. In mouse models of neurodegenerative diseases including AD, P2RY12 immunoreactivity in the brain is reduced at onset and disease peak but restored during recovery [65]. These findings suggest that P2RY12 expression levels in cerebral microglia serve as a biomarker to evaluate pathological severity in the context of $\mathrm{AD}$. This view is further supported by our findings showing that the P2RY12 expression levels are negatively correlated with fibrillar $\mathrm{A} \beta$ deposition (X34 positive plaques) but positively correlated with $\mathrm{MAP}^{+}$dendritic density and PSD-95 ${ }^{+}$post-synaptic puncta in the brains of aged APP/PS1 mice. Notably, SCF+G-CSF treatment increases the $\mathrm{P} 2 \mathrm{RY} 12^{+}$microglia in the cortex and hippocampus, and augments $\mathrm{P} 2 \mathrm{RY} 12^{+} / \mathrm{Iba} 1^{+}$cells distant from the $A \beta$ plaque regions in aged APP/PS1 mice. Our findings indicate that $\mathrm{SCF}+\mathrm{G}-\mathrm{CSF}$ treatment improves the recovery of homeostatic phenotype of microglia and ameliorates pathological severity in the brains of aged APP/PS1 mice. The SCF+G-CSF treatment-enhanced recovery of homeostatic microglia in the brains of aged APP/PS1 mice is further supported by our findings in analyses of TMEM119 immunoreactivity and the branches in P2RY $12^{+}$microglia. The reduced TMEM119 ${ }^{+}$ homeostatic microglia and decreased branches of the $\mathrm{P} 2 \mathrm{RY} 12^{+}$homeostatic microglia in the cortex of aged APP/PS1 mice are reversed by SCF+G-CSF treatment. It requires further examinations to elucidate how $\mathrm{SCF}+\mathrm{G}-$ CSF treatment enhances the recovery of homeostatic microglia in the brain of aged APP/PS1 mice. We propose that interventional molecules/chemicals targeting $A \beta$ clearance and modulating microglial transition into homeostatic phenotype would be helpful therapeutic approaches to restrict pathological progression in AD.

Microglial activation has been thought to be essential for the clearance of accumulated $A \beta$ in the brains of transgenic mouse models of $\mathrm{AD}[84,85]$. However, chronically activated microglia continuously secrete proinflammatory mediators, leading to persistent neuroinflammation in $\mathrm{AD}$. The inflammatory events may compromise the beneficial role of microglia on phagocytosis and degradation of $A \beta[49,86]$. Therefore, an ideal therapeutic approach for $\mathrm{AD}$ would target not only the enhancement of $A \beta$ removal but also inhibition of neuroinflammation. Neurotoxicity caused by elevated inflammatory response plays a crucial role in the progression of $\mathrm{AD}[87,88]$. It has been evidenced that IL4 , an anti-inflammatory cytokine, ameliorates $A \beta$-induced neuroinflammation [89]. NOS-2 is a pro-inflammatory enzyme producing the inflammatory mediator nitric oxide [90]. Increased expression of NOS-2 is involved in the neuronal damage induced by $A \beta$ injection [91]. We have 
observed that both IL-4 and NOS-2 are expressed in cerebral neurons and microglia. In addition, $\mathrm{SCF}+\mathrm{G}-\mathrm{CSF}$ treatment decreases the expression of NOS-2 and increases the levels of IL-4 in the brains of APP/PS1 mice. This observation demonstrates that $\mathrm{SCF}+\mathrm{G}-\mathrm{CSF}$ treatment reduces neuroinflammation in the brains of aged APP/PS1 mice.

It has been documented that $A \beta$ accumulation and chronic neuroinflammation-induced dendritic loss play a vital role in cognition impairments in APP/PS1 mice [56, 57, 92-94]. MAP2 is a neuron-specific cytoskeletal protein that is enriched in the dendrites. MAP2 has been shown to be crucially involved in determining and stabilizing dendritic shape [95]. MAP2 expression is decreased in 6 or 8-month-old APP/PS1 mice as compared to the age-matched controls [96, 97]. PSD-95, a post-synaptic marker, is essential for maintaining the function of the synapse. Reduced PSD-95 is also seen in the 8 or 12-month-old APP/PS1 mice [98, 99]. In line with these studies, we have observed that both the MAP2 ${ }^{+}$ dendrites and PSD-95 ${ }^{+}$post-synapses are decreased in 2627-month-old APP/PS1 mice as compared to age-matched WT controls. SCF+G-CSF treatment ameliorates the loss of $\mathrm{MAP}^{+}$dendrites and PSD-95 ${ }^{+}$synapses in the cortex and hippocampal CA1 of aged APP/PS1 mice. The precise mechanism underlying the SCF+G-CSFincreased dendrites and synapses in aged APP/PS1 mice remains unknown. SCF+G-CSF treatment in aged APP/PS1 mice enhances $A \beta$ removal and reduces neuroinflammation, suggesting that the $\mathrm{SCF}+\mathrm{G}-\mathrm{CSF}-$ ameliorated pathological severity in the brain of aged APP/PS1 mice may be beneficial to the maintenance of dendrites and synapses. In addition, our previous study has demonstrated a direct effect of SCF and G-CSF in supporting neurite extension. SCF+G-CSF synergistically enhances neurite extension and neural network structure formation in cultured primary cortical neurons [26]. In a mouse model of chronic stroke, we have also observed that $\mathrm{SCF}+\mathrm{G}-\mathrm{CSF}$ treatment increases $\mathrm{MAP}^{+}$dendrites and PSD-95 ${ }^{+}$synapses in the ipsilesional cortex [28]. Thus, SCF+G-CSF may restrict dendritic and synaptic loss by promoting the growth of dendrites and synapses in the brains of aged APP/PS1 mice. Furthermore, a study reported by Biscaro and co-workers shows that inhibition of microglial activation protects hippocampal neurogenesis in APP/PS1 mice [100]. On the other hand, accumulating evidence reveals that microglia are essentially involved in synaptic circuit formation and refinement, as well as synaptic excitability and function in the physiologic state of the developing or the adult brain [101-104]. In the present study, we have observed that the $\mathrm{P} 2 \mathrm{RY} 12^{+}$homeostatic microglial area is positively correlated with the MAP2 ${ }^{+}$dendritic area and PSD-95 ${ }^{+}$synaptic puncta, indicating that the $\mathrm{SCF}+\mathrm{G}-$
CSF-increased resting microglia and $\mathrm{SCF}+\mathrm{G}-\mathrm{CSF}-$ improved homeostasis of brain microenvironment may play supportive and reparative roles in maintaining dendrites and synapses in the brains of aged APP/PS1 mice. Finally, intracellular pathological tau aggregation in neurons has been shown to accelerate post-synapse loss in the dendrites [105]. A $\beta$ interaction with pathological tau has recently been proposed as a major pathomechanism in AD [106, 107]. Spontaneous accumulation of tau aggregates has been observed in the brain of aged APP/PS1 mice [59]. Our findings reveal that the size of aggregated tau $\left(\mathrm{AT}^{+}\right.$puncta) in the cortex of aged APP/PS1 mice is reduced by SCF+G-CSF treatment. Further studies are needed, however, to explore how $\mathrm{SCF}+\mathrm{G}-\mathrm{CSF}$ treatment in aged APP/PS1 mice restricts pathological tau aggregation.

The limitations of the present study are the lack of a biochemistry approach to validate our observations in immunohistochemistry and the lack of a control group with SCF+G-CSF treatment in age-matched WT mice to determine whether the SCF+G-CSF-ameliorated neuroinflammation and synaptic loss are the results of decreasing $A \beta$ load.

In total, the present study provides the evidence that $\mathrm{SCF}+\mathrm{G}-\mathrm{CSF}$ treatment increases $\mathrm{A} \beta$ clearance, promotes recovery of homeostatic microglia, decreases inflammation, reduces aggregated tau, and restricts the loss of dendrites and synapses in the brains of aged male APP/PS1 transgenic mice. SCF+G-CSF-enhanced DAM accumulation surrounding the $A \beta$ plaques for removing pathological $\mathrm{A} \beta$, together with the $\mathrm{SCF}+\mathrm{G}-\mathrm{CSF}$-enhanced recovery of homeostatic microglia distant from the $A \beta$ plaques for maintaining dendrites and synapses are the unique modulation processes to restrict $\mathrm{AD}$ pathology and promote brain repair in the context of AD. Our results indicate that the combination of two hematopoietic growth factors, SCF and G-CSF, may have therapeutic potential for $\mathrm{AD}$, even at the late-stage.

\section{Acknowledgements}

We thank Sharon Longo for her technical assistance, Sandra McGillis, Michele Kyle and Karen Hughes for their assistance with proofreading and Xuecheng Qiu for his assistance in formatting references. This study was supported by the National Institute on Aging of the National Institutes of Health in the United States (R01AG051674 to Zhao LR, R01AG051500 to Morgan D).

\section{Conflict of Interest}

The authors declare that they have no competing interests. 


\section{Supplementary Materials}

The Supplemenantry data can be found online at: www.aginganddisease.org/EN/10.14336/AD.2020.0201.

\section{References}

[1] Nichols E, Szoeke CE, Vollset SE, Abbasi N, AbdAllah F, Abdela J, et al. (2019). Global, regional, and national burden of Alzheimer's disease and other dementias, 1990-2016: a systematic analysis for the Global Burden of Disease Study 2016. The Lancet Neurology, 18:88-106.

[2] Gaugler J, James B, Johnson T, Marin A, Weuve J (2019). 2019 Alzheimer's disease facts and figures. ALZHEIMERS \& DEMENTIA, 15:321-387.

[3] Armstrong RA (2006). Plaques and tangles and the pathogenesis of Alzheimer's disease. Folia Neuropathol, 44:1-11.

[4] Heneka MT, Carson MJ, El Khoury J, Landreth GE, Brosseron F, Feinstein DL, et al. (2015). Neuroinflammation in Alzheimer's disease. Lancet Neurol, 14:388-405.

[5] Vetrivel KS, Thinakaran G (2006). Amyloidogenic processing of beta-amyloid precursor protein in intracellular compartments. Neurology, 66:S69-73.

[6] Palop JJ, Mucke L (2010). Amyloid-beta-induced neuronal dysfunction in Alzheimer's disease: from synapses toward neural networks. Nat Neurosci, 13:812-818

[7] Diaz A, Limon D, Chavez R, Zenteno E, Guevara J (2012). Abeta25-35 injection into the temporal cortex induces chronic inflammation that contributes to neurodegeneration and spatial memory impairment in rats. J Alzheimers Dis, 30:505-522.

[8] Pujadas L, Rossi D, Andres R, Teixeira CM, SerraVidal B, Parcerisas A, et al. (2014). Reelin delays amyloid-beta fibril formation and rescues cognitive deficits in a model of Alzheimer's disease. Nat Commun, 5:3443.

[9] Janus C, Pearson J, McLaurin J, Mathews PM, Jiang Y, Schmidt SD, et al. (2000). A beta peptide immunization reduces behavioural impairment and plaques in a model of Alzheimer's disease. Nature, 408:979-982.

[10] Kennedy ME, Stamford AW, Chen X, Cox K, Cumming JN, Dockendorf MF, et al. (2016). The BACE1 inhibitor verubecestat (MK-8931) reduces CNS beta-amyloid in animal models and in Alzheimer's disease patients. Sci Transl Med, 8:363ra150.

[11] Graham WV, Bonito-Oliva A, Sakmar TP (2017). Update on Alzheimer's Disease Therapy and Prevention Strategies. Annu Rev Med, 68:413-430.

[12] Sevigny J, Chiao P, Bussiere T, Weinreb PH, Williams L, Maier M, et al. (2016). The antibody aducanumab reduces Abeta plaques in Alzheimer's disease. Nature, 537:50-56.

[13] van Dyck CH (2018). Anti-Amyloid-beta Monoclonal
Antibodies for Alzheimer's Disease: Pitfalls and Promise. Biol Psychiatry, 83:311-319.

Wilcock DM, DiCarlo G, Henderson D, Jackson J, Clarke K, Ugen KE, et al. (2003). Intracranially administered anti-Abeta antibodies reduce betaamyloid deposition by mechanisms both independent of and associated with microglial activation. J Neurosci, 23:3745-3751.

[15] Wilcock DM, Rojiani A, Rosenthal A, Subbarao S, Freeman MJ, Gordon MN, et al. (2004). Passive immunotherapy against Abeta in aged APP-transgenic mice reverses cognitive deficits and depletes parenchymal amyloid deposits in spite of increased vascular amyloid and microhemorrhage. $\mathrm{J}$ Neuroinflammation, 1:24.

[16] Morgan D (2011). Immunotherapy for Alzheimer's disease. Journal of Internal Medicine, 269:54-63.

[17] Salloway S, Sperling R, Gilman S, Fox NC, Blennow $\mathrm{K}$, Raskind M, et al. (2009). A phase 2 multiple ascending dose trial of bapineuzumab in mild to moderate Alzheimer disease. Neurology, 73:20612070.

[18] Schneider L (2020). A resurrection of aducanumab for Alzheimer's disease. The Lancet Neurology, 19:111112.

[19] Pfeifer M, Boncristiano S, Bondolfi L, Stalder A, Deller T, Staufenbiel M, et al. (2002). Cerebral hemorrhage after passive anti-Abeta immunotherapy. Science, 298:1379.

[20] Welte K, Platzer E, Lu L, Gabrilove JL, Levi E, Mertelsmann R, et al. (1985). Purification and biochemical characterization of human pluripotent hematopoietic colony-stimulating factor. Proceedings of the National Academy of Sciences, 82:1526-1530.

[21] Zsebo KM, Wypych J, McNiece IK, Lu HS, Smith KA, Karkare SB, et al. (1990). Identification, purification, and biological characterization of hematopoietic stem cell factor from buffalo rat liver-conditioned medium. Cell, 63:195-201.

[22] Duarte RF, Frank DA (2000). SCF and G-CSF lead to the synergistic induction of proliferation and gene expression through complementary signaling pathways. Blood, 96:3422-3430.

[23] Briddell R, Hartley C, Smith K, McNiece I (1993). Recombinant rat stem cell factor synergizes with recombinant human granulocyte colony-stimulating factor in vivo in mice to mobilize peripheral blood progenitor cells that have enhanced repopulating potential. Blood, 82:1720-1723.

[24] Duarte RF, Franf DA (2002). The synergy between stem cell factor (SCF) and granulocyte colonystimulating factor (G-CSF): molecular basis and clinical relevance. Leuk Lymphoma, 43:1179-1187.

[25] Hess DA, Levac KD, Karanu FN, Rosu-Myles M, White MJ, Gallacher L, et al. (2002). Functional analysis of human hematopoietic repopulating cells mobilized with granulocyte colony-stimulating factor alone versus granulocyte colony-stimulating factor in combination with stem cell factor. Blood, 100:869-878. Su Y, Cui L, Piao C, Li B, Zhao LR (2013). The effects 
of hematopoietic growth factors on neurite outgrowth. PLoS One, 8:e75562.

[27] Zhao L-R, Berra HH, Duan W-M, Singhal S, Mehta J, Apkarian AV, et al. (2007). Beneficial effects of hematopoietic growth factor therapy in chronic ischemic stroke in rats. Stroke, 38:2804-2811.

[28] Cui L, Murikinati SR, Wang D, Zhang X, Duan WM, Zhao LR (2013). Reestablishing neuronal networks in the aged brain by stem cell factor and granulocytecolony stimulating factor in a mouse model of chronic stroke. PLoS One, 8:e64684.

[29] Cui L, Duchamp NS, Boston DJ, Ren X, Zhang X, Hu $\mathrm{H}$, et al. (2015). NF-кB is involved in brain repair by stem cell factor and granulocyte-colony stimulating factor in chronic stroke. Experimental neurology, 263:17-27.

[30] Laske C, Stellos K, Stransky E, Seizer P, Akcay O, Eschweiler GW, et al. (2008). Decreased plasma and cerebrospinal fluid levels of stem cell factor in patients with early Alzheimer's disease. J Alzheimers Dis, 15:451-460.

[31] Laske C, Stellos K, Stransky E, Leyhe T, Gawaz M (2009). Decreased plasma levels of granulocytecolony stimulating factor (G-CSF) in patients with early Alzheimer's disease. J Alzheimers Dis, 17:115123.

[32] Li B, Gonzalez-Toledo ME, Piao CS, Gu A, Kelley RE, Zhao LR (2011). Stem cell factor and granulocyte colony-stimulating factor reduce beta-amyloid deposits in the brains of APP/PS1 transgenic mice. Alzheimers Res Ther, 3:8.

[33] Jankowsky JL, Slunt HH, Ratovitski T, Jenkins NA, Copeland NG, Borchelt DR (2001). Co-expression of multiple transgenes in mouse CNS: a comparison of strategies. Biomol Eng, 17:157-165.

[34] Jankowsky JL, Fadale DJ, Anderson J, Xu GM, Gonzales V, Jenkins NA, et al. (2004). Mutant presenilins specifically elevate the levels of the 42 residue beta-amyloid peptide in vivo: evidence for augmentation of a 42-specific gamma secretase. Hum Mol Genet, 13:159-170.

[35] Zhao LR, Navalitloha Y, Singhal S, Mehta J, Piao CS, Guo WP, et al. (2007). Hematopoietic growth factors pass through the blood-brain barrier in intact rats. Exp Neurol, 204:569-573.

[36] Zhao LR, Berra HH, Duan WM, Singhal S, Mehta J, Apkarian AV, et al. (2007). Beneficial effects of hematopoietic growth factor therapy in chronic ischemic stroke in rats. Stroke, 38:2804-2811.

[37] Piao CS, Gonzalez-Toledo ME, Gu X, Zhao LR (2012). The combination of stem cell factor and granulocytecolony stimulating factor for chronic stroke treatment in aged animals. Exp Transl Stroke Med, 4:25.

[38] Spillantini MG, Goedert M, Jakes R, Klug A (1990). Different configurational states of beta-amyloid and their distributions relative to plaques and tangles in Alzheimer disease. Proc Natl Acad Sci U S A, 87:3947-3951.

[39] Serpell LC (2000). Alzheimer's amyloid fibrils: structure and assembly. Biochim Biophys Acta,
[40] Chen GF, Xu TH, Yan Y, Zhou YR, Jiang Y, Melcher $\mathrm{K}$, et al. (2017). Amyloid beta: structure, biology and structure-based therapeutic development. Acta Pharmacol Sin, 38:1205-1235.

[41] Kress GJ, Liao F, Dimitry J, Cedeno MR, FitzGerald GA, Holtzman DM, et al. (2018). Regulation of amyloid-beta dynamics and pathology by the circadian clock. J Exp Med, 215:1059-1068.

[42] Govindpani K, McNamara LG, Smith NR, Vinnakota C, Waldvogel HJ, Faull RL, et al. (2019). Vascular Dysfunction in Alzheimer's Disease: A Prelude to the Pathological Process or a Consequence of It? J Clin Med, 8.

[43] Jiang T, Tan L, Zhu XC, Zhang QQ, Cao L, Tan MS, et al. (2014). Upregulation of TREM2 ameliorates neuropathology and rescues spatial cognitive impairment in a transgenic mouse model of Alzheimer's disease. Neuropsychopharmacology, 39:2949-2962.

[44] Kim SM, Mun BR, Lee SJ, Joh Y, Lee HY, Ji KY, et al. (2017). TREM2 promotes Abeta phagocytosis by upregulating $\quad \mathrm{C} /$ EBPalpha-dependent $\quad \mathrm{CD} 36$ expression in microglia. Sci Rep, 7:11118.

[45] Chistiakov DA, Killingsworth MC, Myasoedova VA, Orekhov AN, Bobryshev YV (2017). CD68/macrosialin: not just a histochemical marker. Lab Invest, 97:4-13.

[46] Wilkinson K, El Khoury J (2012). Microglial scavenger receptors and their roles in the pathogenesis of Alzheimer's disease. Int $\mathrm{J}$ Alzheimers Dis, 2012:489456.

[47] Zotova E, Bharambe V, Cheaveau M, Morgan W, Holmes C, Harris S, et al. (2013). Inflammatory components in human Alzheimer's disease and after active amyloid-beta42 immunization. Brain, 136: 2677-2696.

[48] Daria A, Colombo A, Llovera G, Hampel H, Willem M, Liesz A, et al. (2017). Young microglia restore amyloid plaque clearance of aged microglia. EMBO J, 36:583-603.

[49] Koenigsknecht-Talboo J, Landreth GE (2005). Microglial phagocytosis induced by fibrillar betaamyloid and IgGs are differentially regulated by proinflammatory cytokines. J Neurosci, 25:8240-8249. Spangenberg EE, Green KN (2017). Inflammation in Alzheimer's disease: Lessons learned from microgliadepletion models. Brain Behav Immun, 61:1-11.

[51] Butovsky O, Jedrychowski MP, Moore CS, Cialic R, Lanser AJ, Gabriely G, et al. (2014). Identification of a unique TGF-beta-dependent molecular and functional signature in microglia. Nat Neurosci, 17:131-143.

[52] Butovsky O, Jedrychowski MP, Cialic R, Krasemann S, Murugaiyan G, Fanek Z, et al. (2015). Targeting miR-155 restores abnormal microglia and attenuates disease in SOD1 mice. Ann Neurol, 77:75-99.

[53] Zrzavy T, Hametner S, Wimmer I, Butovsky O, Weiner HL, Lassmann H (2017). Loss of 'homeostatic' microglia and patterns of their activation in active 
multiple sclerosis. Brain, 140:1900-1913.

[54] Nimmerjahn A, Kirchhoff F, Helmchen F (2005). Resting microglial cells are highly dynamic surveillants of brain parenchyma in vivo. Science, 308:1314-1318.

[55] Rao Y, Liang YX, Peng B (2017). A revisit of rod microglia in preclinical studies. Neural Regen Res, 12:56-57.

[56] Lacor PN, Buniel MC, Furlow PW, Clemente AS, Velasco PT, Wood M, et al. (2007). Abeta oligomerinduced aberrations in synapse composition, shape, and density provide a molecular basis for loss of connectivity in Alzheimer's disease. J Neurosci, 27:796-807.

[57] Sanjari Moghaddam H, Aarabi MH (2018). AbetaMediated Dysregulation of F-Actin Nanoarchitecture Leads to Loss of Dendritic Spines and Alzheimer's Disease-Related Cognitive Impairments. J Neurosci, 38:5840-5842.

[58] Thal DR, Griffin WS, Braak H (2008). Parenchymal and vascular Abeta-deposition and its effects on the degeneration of neurons and cognition in Alzheimer's disease. J Cell Mol Med, 12:1848-1862.

[59] Metaxas A, Thygesen C, Kempf SJ, Anzalone M, Vaitheeswaran R, Petersen S, et al. (2019). Ageing and amyloidosis underlie the molecular and pathological alterations of tau in a mouse model of familial Alzheimer's disease. Sci Rep, 9:15758.

[60] Ginhoux F, Lim S, Hoeffel G, Low D, Huber T (2013). Origin and differentiation of microglia. Front Cell Neurosci, 7:45.

[61] Streit WJ, Braak H, Xue QS, Bechmann I (2009). Dystrophic (senescent) rather than activated microglial cells are associated with tau pathology and likely precede neurodegeneration in Alzheimer's disease. Acta Neuropathol, 118:475-485.

[62] Keren-Shaul H, Spinrad A, Weiner A, MatcovitchNatan O, Dvir-Szternfeld R, Ulland TK, et al. (2017). A Unique Microglia Type Associated with Restricting Development of Alzheimer's Disease. Cell, 169:12761290 e1217.

[63] Navarro V, Sanchez-Mejias E, Jimenez S, MunozCastro C, Sanchez-Varo R, Davila JC, et al. (2018). Microglia in Alzheimer's Disease: Activated, Dysfunctional or Degenerative. Front Aging Neurosci, 10:140.

[64] Sala Frigerio C, Wolfs L, Fattorelli N, Thrupp N, Voytyuk I, Schmidt I, et al. (2019). The Major Risk Factors for Alzheimer's Disease: Age, Sex, and Genes Modulate the Microglia Response to Abeta Plaques. Cell Rep, 27:1293-1306 e1296.

[65] Krasemann S, Madore C, Cialic R, Baufeld C, Calcagno N, El Fatimy R, et al. (2017). The TREM2APOE Pathway Drives the Transcriptional Phenotype of Dysfunctional Microglia in Neurodegenerative Diseases. Immunity, 47:566-581 e569.

[66] Sanchez-Mejias E, Navarro V, Jimenez S, SanchezMico M, Sanchez-Varo R, Nunez-Diaz C, et al. (2016). Soluble phospho-tau from Alzheimer's disease hippocampus drives microglial degeneration. Acta
Neuropathol, 132:897-916.

[67] Hemonnot AL, Hua J, Ulmann L, Hirbec H (2019). Microglia in Alzheimer Disease: Well-Known Targets and New Opportunities. Front Aging Neurosci, 11:233. [68] Monasor LS, Müller SA, Colombo A, König J, Roth S, Liesz A, et al. (2019). Fibrillar A $\beta$ triggers microglial proteome alterations and dysfunction in Alzheimer mouse models. bioRxiv.

[69] Colonna M, Wang Y (2016). TREM2 variants: new keys to decipher Alzheimer disease pathogenesis. Nat Rev Neurosci, 17:201-207.

[70] Boissonneault V, Filali M, Lessard M, Relton J, Wong G, Rivest S (2009). Powerful beneficial effects of macrophage colony-stimulating factor on betaamyloid deposition and cognitive impairment in Alzheimer's disease. Brain, 132:1078-1092.

[71] Boyd TD, Bennett SP, Mori T, Governatori N, Runfeldt M, Norden M, et al. (2010). GM-CSF upregulated in rheumatoid arthritis reverses cognitive impairment and amyloidosis in Alzheimer mice. $\mathrm{J}$ Alzheimers Dis, 21:507-518.

[72] Smith AM, Gibbons HM, Oldfield RL, Bergin PM, Mee EW, Curtis MA, et al. (2013). M-CSF increases proliferation and phagocytosis while modulating receptor and transcription factor expression in adult human microglia. J Neuroinflammation, 10:85.

[73] Sanchez-Ramos J, Song S, Sava V, Catlow B, Lin X, Mori T, et al. (2009). Granulocyte colony stimulating factor decreases brain amyloid burden and reverses cognitive impairment in Alzheimer's mice. Neuroscience, 163:55-72.

[74] Sanchez-Ramos J, Cimino C, Avila R, Rowe A, Chen R, Whelan G, et al. (2012). Pilot study of granulocytecolony stimulating factor for treatment of Alzheimer's disease. J Alzheimers Dis, 31:843-855.

[75] Simard AR, Soulet D, Gowing G, Julien JP, Rivest S (2006). Bone marrow-derived microglia play a critical role in restricting senile plaque formation in Alzheimer's disease. Neuron, 49:489-502.

[76] Majumdar A, Cruz D, Asamoah N, Buxbaum A, Sohar I, Lobel P, et al. (2007). Activation of microglia acidifies lysosomes and leads to degradation of Alzheimer amyloid fibrils. Mol Biol Cell, 18:14901496.

[77] Cheng-Hathaway PJ, Reed-Geaghan EG, Jay TR, Casali BT, Bemiller SM, Puntambekar SS, et al. (2018). The Trem2 R47H variant confers loss-offunction-like phenotypes in Alzheimer's disease. Mol Neurodegener, 13:29.

[78] Jonsson T, Stefansson H, Steinberg S, Jonsdottir I, Jonsson PV, Snaedal J, et al. (2013). Variant of TREM2 associated with the risk of Alzheimer's disease. N Engl J Med, 368:107-116.

[79] Garcia-Revilla J, Alonso-Bellido IM, Burguillos MA, Herrera AJ, Espinosa-Oliva AM, Ruiz R, et al. (2019). Reformulating Pro-Oxidant Microglia in Neurodegeneration. J Clin Med, 8.

[80] Jay TR, Miller CM, Cheng PJ, Graham LC, Bemiller $\mathrm{S}$, Broihier ML, et al. (2015). TREM2 deficiency eliminates TREM2+ inflammatory macrophages and 
ameliorates pathology in Alzheimer's disease mouse models. J Exp Med, 212:287-295.

[81] Rangaraju S, Dammer EB, Raza SA, Rathakrishnan P, Xiao H, Gao T, et al. (2018). Identification and therapeutic modulation of a pro-inflammatory subset of disease-associated-microglia in Alzheimer's disease. Mol Neurodegener, 13:24.

[82] Haynes SE, Hollopeter G, Yang G, Kurpius D, Dailey ME, Gan WB, et al. (2006). The P2Y12 receptor regulates microglial activation by extracellular nucleotides. Nat Neurosci, 9:1512-1519.

[83] Lai MK, Tan MG, Kirvell S, Hobbs C, Lee J, Esiri MM, et al. (2008). Selective loss of P2Y2 nucleotide receptor immunoreactivity is associated with Alzheimer's disease neuropathology. J Neural Transm (Vienna), 115:1165-1172.

[84] Frautschy SA, Yang F, Irrizarry M, Hyman B, Saido TC, Hsiao K, et al. (1998). Microglial response to amyloid plaques in APPsw transgenic mice. Am J Pathol, 152:307-317.

[85] Herber DL, Mercer M, Roth LM, Symmonds K, Maloney J, Wilson N, et al. (2007). Microglial activation is required for Abeta clearance after intracranial injection of lipopolysaccharide in APP transgenic mice. J Neuroimmune Pharmacol, 2:222231.

[86] Benzing WC, Wujek JR, Ward EK, Shaffer D, Ashe $\mathrm{KH}$, Younkin SG, et al. (1999). Evidence for glialmediated inflammation in aged $\mathrm{APP}(\mathrm{SW})$ transgenic mice. Neurobiol Aging, 20:581-589.

[87] Casali BT, Reed-Geaghan EG, Landreth GE (2018). Nuclear receptor agonist-driven modification of inflammation and amyloid pathology enhances and sustains cognitive improvements in a mouse model of Alzheimer's disease. J Neuroinflammation, 15:43.

[88] Yuskaitis CJ, Jope RS (2009). Glycogen synthase kinase-3 regulates microglial migration, inflammation, and inflammation-induced neurotoxicity. Cell Signal, 21:264-273.

[89] Lyons A, Griffin RJ, Costelloe CE, Clarke RM, Lynch MA (2007). IL-4 attenuates the neuroinflammation induced by amyloid-beta in vivo and in vitro. $\mathrm{J}$ Neurochem, 101:771-781.

[90] Pfeilschifter J (2002). Nitric oxide triggers the expression of proinflammatory and protective gene products in mesangial cells and the inflamed glomerulus. Nephrol Dial Transplant, 17:347-348.

[91] Kalinin S, Polak PE, Madrigal JL, Gavrilyuk V, Sharp A, Chauhan N, et al. (2006). Beta-amyloid-dependent expression of NOS2 in neurons: prevention by an alpha2-adrenergic antagonist. Antioxid Redox Signal, 8:873-883.

[92] Heneka MT, Kummer MP, Stutz A, Delekate A, Schwartz S, Vieira-Saecker A, et al. (2013). NLRP3 is activated in Alzheimer's disease and contributes to pathology in APP/PS1 mice. Nature, 493:674-678.

[93] Talantova M, Sanz-Blasco S, Zhang X, Xia P, Akhtar MW, Okamoto S, et al. (2013). Abeta induces astrocytic glutamate release, extrasynaptic NMDA receptor activation, and synaptic loss. Proc Natl Acad
Sci U S A, 110:E2518-2527.

[94] Zou C, Shi Y, Ohli J, Schuller U, Dorostkar MM, Herms J (2016). Neuroinflammation impairs adaptive structural plasticity of dendritic spines in a preclinical model of Alzheimer's disease. Acta Neuropathol, 131:235-246.

[95] Lim RW, Halpain S (2000). Regulated association of microtubule-associated protein 2 (MAP2) with Src and Grb2: evidence for MAP2 as a scaffolding protein. J Biol Chem, 275:20578-20587.

[96] Nunes AF, Amaral JD, Lo AC, Fonseca MB, Viana RJ, Callaerts-Vegh Z, et al. (2012). TUDCA, a bile acid, attenuates amyloid precursor protein processing and amyloid-beta deposition in APP/PS1 mice. Mol Neurobiol, 45:440-454.

[97] Qiao J, Wang J, Wang H, Zhang Y, Zhu S, Adilijiang A, et al. (2016). Regulation of astrocyte pathology by fluoxetine prevents the deterioration of Alzheimer phenotypes in an APP/PS1 mouse model. Glia, 64:240-254.

[98] Woo JA, Boggess T, Uhlar C, Wang X, Khan H, Cappos G, et al. (2015). RanBP9 at the intersection between cofilin and Abeta pathologies: rescue of neurodegenerative changes by RanBP9 reduction. Cell Death Dis, 6:1676.

[99] Xu Z, Xiao N, Chen Y, Huang H, Marshall C, Gao J, et al. (2015). Deletion of aquaporin-4 in APP/PS1 mice exacerbates brain Abeta accumulation and memory deficits. Mol Neurodegener, 10:58.

[100] Biscaro B, Lindvall O, Tesco G, Ekdahl CT, Nitsch RM (2012). Inhibition of microglial activation protects hippocampal neurogenesis and improves cognitive deficits in a transgenic mouse model for Alzheimer's disease. Neurodegener Dis, 9:187-198.

[101] Baalman K, Marin MA, Ho TS, Godoy M, Cherian L, Robertson C, et al. (2015). Axon initial segmentassociated microglia. J Neurosci, 35:2283-2292.

[102] Miyamoto A, Wake H, Moorhouse AJ, Nabekura J (2013). Microglia and synapse interactions: fine tuning neural circuits and candidate molecules. Front Cell Neurosci, 7:70.

[103] Tremblay ME, Stevens B, Sierra A, Wake H, Bessis A, Nimmerjahn A (2011). The role of microglia in the healthy brain. J Neurosci, 31:16064-16069.

[104] Wake H, Moorhouse AJ, Miyamoto A, Nabekura J (2013). Microglia: actively surveying and shaping neuronal circuit structure and function. Trends Neurosci, 36:209-217.

[105] Jadhav S, Cubinkova V, Zimova I, Brezovakova V, Madari A, Cigankova V, et al. (2015). Tau-mediated synaptic damage in Alzheimer's disease. Transl Neurosci, 6:214-226.

[106] Polanco JC, Li C, Bodea LG, Martinez-Marmol R, Meunier FA, Gotz J (2018). Amyloid-beta and tau complexity - towards improved biomarkers and targeted therapies. Nat Rev Neurol, 14:22-39.

[107] Ittner A, Ittner LM (2018). Dendritic Tau in Alzheimer's Disease. Neuron, 99:13-27. 